\title{
Simulation of the Nanofiltration of Pulping Black Liquor by Dynamic Blade Cross-flow with Membrane
}

\author{
Wenjie Zhao, Zhongyu Du, Ning Kuang, Hao Wang, Benliang Yu, Junfei Wu,* and \\ Fushan Chen \\ This paper investigated the filtration of black liquor with blade cross-flow \\ by membrane. The lignin content in black liquid filtered by the nanofiltration \\ membrane (NP010) is high under the transmembrane pressure of 0.5 bar, \\ 1 bar, 1.5 bar, and 2 bar at $300 \mathrm{rpm}$ and $800 \mathrm{rpm}$. In this regard, the \\ tangential velocity on the nanofiltration membrane surface and the \\ pressure variation on the blade in the process of filtration are simulated \\ and analyzed with Fluent software. The tangential flow velocity on the \\ nanofiltration membrane surface and the dynamic pressure on the blade, \\ as well as the law of change under different rotation speed and \\ transmembrane pressure are obtained. The comparison between \\ experimental and simulated results have validated the numerical model of \\ the filtration of black liquid by the blade dynamic cross-flow. According to \\ the experimental and simulated results, the optimized filtration conditions \\ are obtained when the blade dynamic cross-flow uses $1 \mathrm{kDa}$ nanofiltration \\ membrane to filter black liquor.
}

Keywords: Dynamic cross-flow; Nanomembrane filtration; Tangential velocity; Dynamic pressure

Contact information: College of Electromechanical Engineering, Qingdao University of Science and Technology Qingdao 266061, China; *Corresponding author: wenjienici@ gmail.com

\section{INTRODUCTION}

Ninety percent of the total waste-water pollutants in the paper-making industry has come from the pulping black liquor. Because the pulping black liquor contains lignin, a biomass difficult to degrade, the treatment of black liquor has become a world-wide problem. Therefore, the treatment of pulping black liquor mainly lies in the proper treatment of lignin. However, lignin is a natural renewable aromatic polymer second only to cellulose. It has good mechanical strength, elasticity, and rheology as well as high carbon content, reactivity, and chemical compatibility. These attributes imply that it also has high application value. Therefore, the recycling of lignin from the pulping black liquor not only can solve the environmental pollution in a fundamental sense, but it can also "turn waste into treasure".

Membrane filtration technology uses membranes with different cut-off molecular weights to concentrate pulping black liquor to a certain degree, separate lignin with large molecular weight from sugars and organics with small molecular weight, and to obtain pulping black liquor containing lignin with uniform molecular weight distribution and single structure (Wallberg et al. 2003a,b; Wallberg and Jönsson 2006; Ji et al. 2011; Helander et al. 2013; Arkell et al. 2014; Humpert et al. 2016; Al-Rudainy et al. 2017; Durruty 2018; Liu et al. 2018; Hubbe et al. 2019). However, with the passage of time in the process of filtration, the formation of filter cake increases the filtration resistance (De and Bhattacharya 1996; Costa et al. 2018). The biggest feature of dynamic blade crossflow membrane filtration is that the rotation of the blade causes high shearing stress of the 
liquid on the membrane surface, which reduces the filtration resistance caused by the filter cake, thus improving filtration efficiency (Jaffrin 2008; Jönsson et al. 2008; Toledano et al. 2010a,b; Domínguez-Robles et al. 2016, 2018).

Before the simulation of filtering black liquor by blade cross-flow, initial experiments were carried out in which black liquor was filtered by blade cross-flow ultrafiltration $(5 \mathrm{kDa}, 10 \mathrm{kDa})$ and nanofiltration $(1 \mathrm{kDa})$. The lignin content was measured in the filtered black liquor. The lignin content was $37 \%$ in the nanofiltration experiment and $22 \%$ in the ultrafiltration experiment. Experimental research on lignin retention in black liquor based on dynamic blade cross-flow membrane filtration shows that nanofiltration (NP010-1kDa) has a relatively obvious effect on lignin retention in pulping black liquor. According to the theoretical analysis of the average shearing stress on the membrane surface (Bouzerar et al. 2000; Manttari et al. 2015; Kevlich et al. 2017; Ahuja et al. 2018), the average shearing stress shows a non-linear variation with the blade rotation speed $(\omega)$ and a linear correlation with the blade radial distance ( $r$ ) (Jaffrin 2008). Combining theory with experiments, this paper uses the computational fluid dynamics (CFD) software Fluent to perform numerical simulations of lignin retained in pulping black liquor by blade cross-flow. The main purpose of this paper is to investigate the tangential velocity on the membrane surface and the pressure variation on the blade with the radius when the lignin in the black liquor is filtered by the blade cross-flow. These data provide useful information for the application of the blade dynamic cross-flow process to separate the lignin in the black liquor.

\section{EXPERIMENTAL}

\section{Materials}

Experimental equipment

A DYNO filter provided by BOKELA GmbH (Karlsruhe, Germany) is shown in Fig. 1. The whole process mainly included the control system, data acquisition system, material input system, filtration system, and self-cleaning system. The DYNO filter was composed of rotating blades, filter membranes, stainless steel porous membranes, and other parts. Its basic equipment data are shown in Table 1. The black liquor flowed from vessels into the filter chamber from its inlet through pressure, passed through the polymer membrane and the stainless-steel porous membrane, and finally the filtrate flowed out through the outlet (Bott et al. 2000). Transmembrane pressure (TMP) was controlled by a pressure-measuring valve. The rotor was controlled by a motor and operated at a speed range from $0 \mathrm{rpm}$ to $1000 \mathrm{rpm}$. The rpm and TMP remained constant during the separation process. The weight of the filtered filtrate was measured by a load sensor, and data such as flux in the filtration process was automatically saved on the computer.

\section{Table 1. Basic Data of DYNO Filter}

\begin{tabular}{|c|c|c|c|c|c|c|c|}
\hline $\begin{array}{c}\text { Filter } \\
\text { Area } \\
\left(\mathrm{m}^{2}\right)\end{array}$ & $\begin{array}{c}\text { Module } \\
\text { Diameter } \\
(\mathrm{mm})\end{array}$ & $\begin{array}{c}\text { Maximum } \\
\text { Pressure } \\
(\mathrm{bar})\end{array}$ & $\begin{array}{c}\text { Maximum } \\
\text { Temperature } \\
\left({ }^{\circ} \mathrm{C}\right)\end{array}$ & $\begin{array}{c}\text { Velocity } \\
(\mathrm{m} / \mathrm{s})\end{array}$ & $\begin{array}{c}\text { Dimensions L } \\
\times \mathrm{W} \times \mathrm{H}(\mathrm{mm})\end{array}$ & $\begin{array}{c}\text { Weight } \\
(\mathrm{kg})\end{array}$ & $\begin{array}{c}\text { Drive } \\
(\mathrm{kW})\end{array}$ \\
\hline 0.013 & 137 & 6 & 95 & 12 & $639 / 334 / 581$ & 48 & 0.55 \\
\hline
\end{tabular}




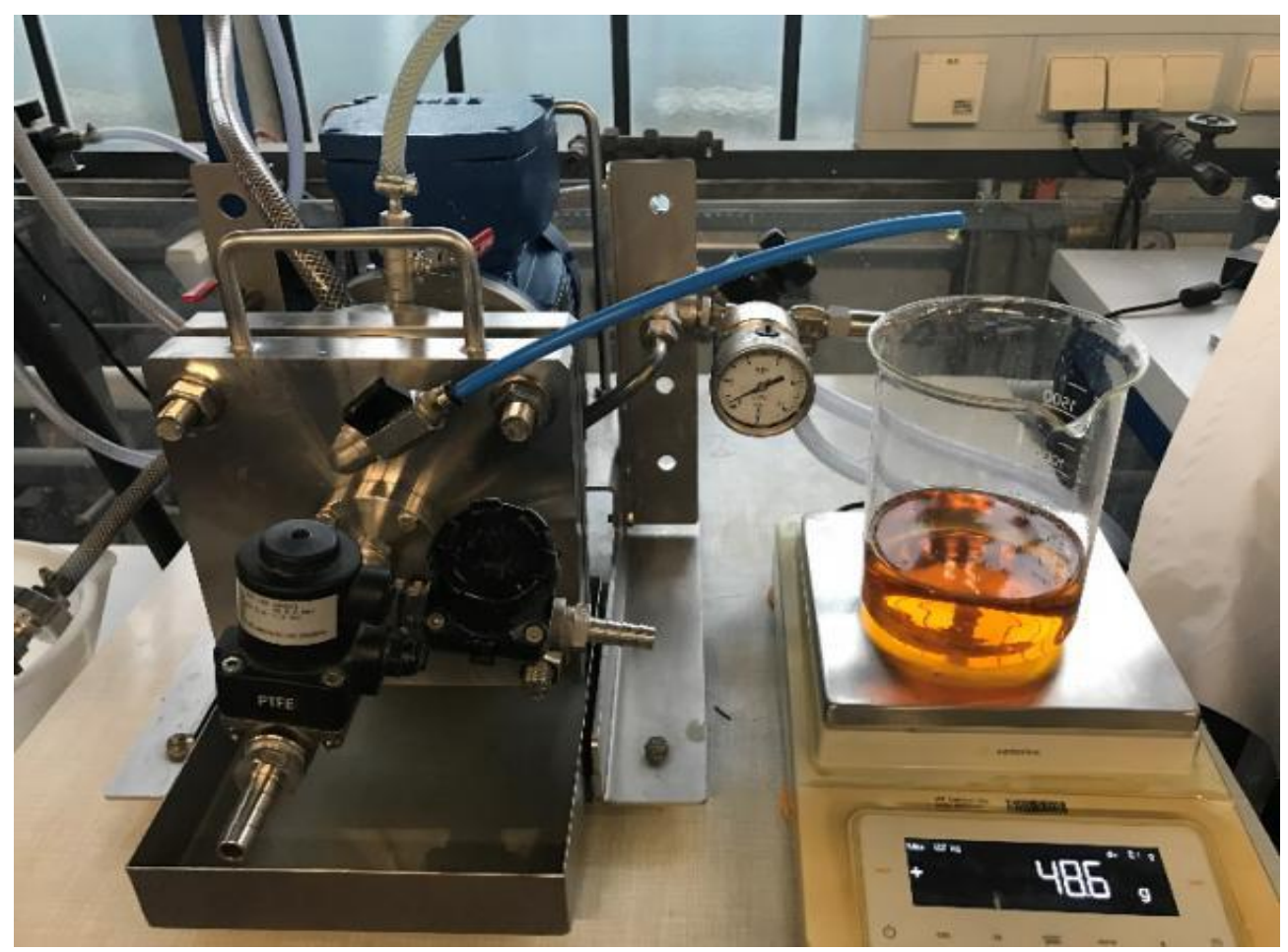

(a)

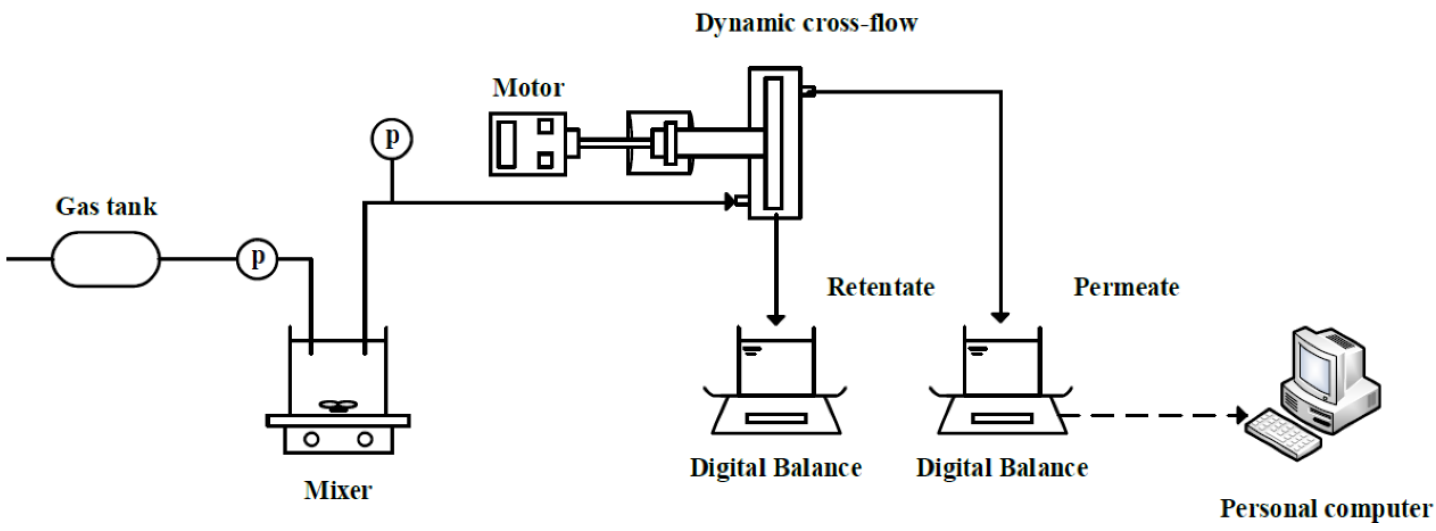

(b)

Fig. 1. Schematic of experimental equipment (a) and process (b)

The membrane used in the experiment was provided by Microdyn Nadir of Germany, and the detailed data of the membrane is described in Table 2. The black liquor used in the experiment was provided by the Institute of Mechanical Process Engineering and Mechanics of Karlsruher Institut of Technologie, and the basic characteristics of black liquor are shown in Table 3.

Table 2. Basic Data on Filter Membranes Used in Experimental Studies

\begin{tabular}{|c|c|c|c|c|}
\hline Name & Material & $\begin{array}{c}\text { Permeability } \\
(\mathrm{LMH} / \text { bar })\end{array}$ & $\mathrm{pH}$ range & $\begin{array}{c}\text { Standard captured } \\
\text { molecular weight (Da) }\end{array}$ \\
\hline Nanofiltration NP010 & PES & $\geq 5$ & $0.0-14.0$ & $1,000-1,200$ \\
\hline Ultrafiltration UP005 & PES & $\geq 10.0$ & $0.0-14.0$ & 5,000 \\
\hline Ultrafiltration UP010 & PES & $\geq 50.0$ & $0.0-14.0$ & 10,000 \\
\hline
\end{tabular}


Table 3. Basic Data on Pulping Black Liquor in Experiments

\begin{tabular}{|c|c|c|c|}
\hline Name & Density $\left(\mathrm{kg} / \mathrm{m}^{3}\right)$ & Viscosity $(\mathrm{Pa} \cdot \mathrm{s})$ & Lignin content $(\%)$ \\
\hline Pulping black liquor & 1098 & 5.85 & 9 \\
\hline
\end{tabular}

\section{Experimental Results}

The experimental conditions were: $300 \mathrm{rpm}, 800 \mathrm{rpm}$; transmembrane pressure is: 0.5 bar, 1 bar, 1.5 bar, $2 \mathrm{~b}$ ar; three filtration membranes: UP005, UP010, NP010. The experimental results of the change of lignin content in black liquid are shown in Fig. 2. The lignin content in the black liquor filtered by nanofiltration membrane was higher than other membranes. By comparing the experimental data, it was found that the effect of the nanofiltration membrane (NP010) was ideal for lignin retention and concentration in black liquid. Figure 3 gives the experimental results of the average flux of black liquid filtered by NP010.

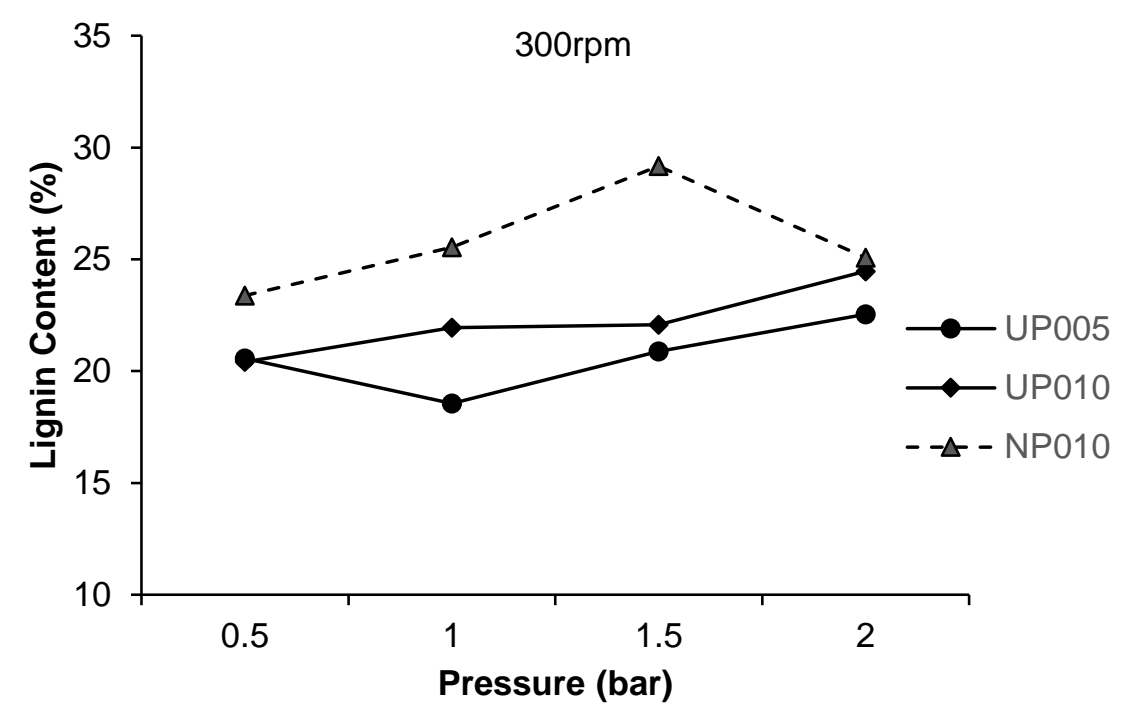

(a)

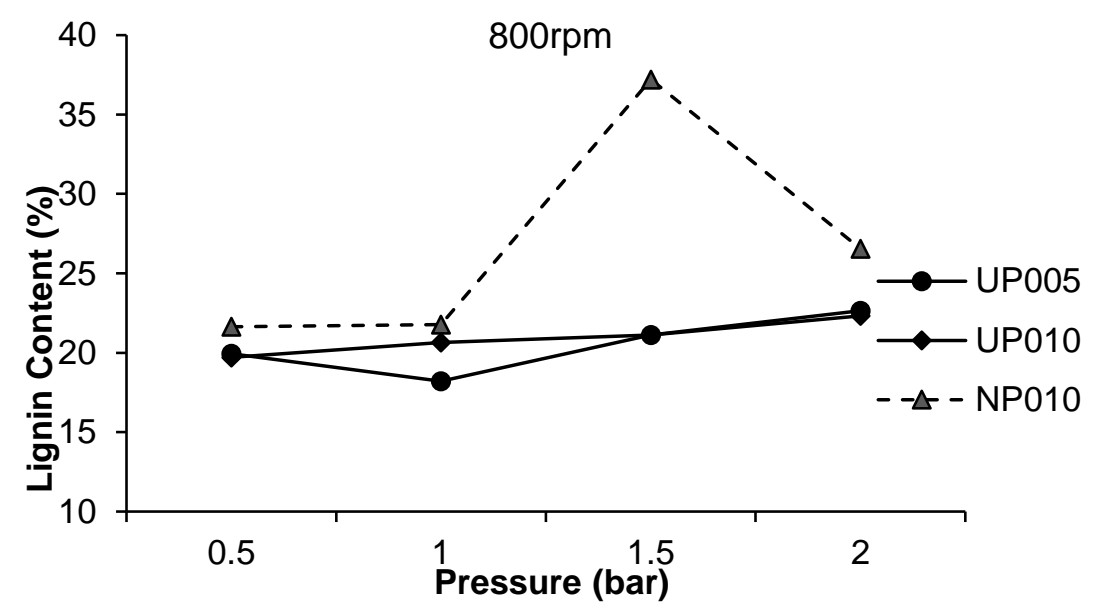

(b)

Fig. 2. Changes in lignin content in membrane-filtered black liquor (a) 300 rpm; (b) 800 rpm 
In the experiment, the nanofiltration membrane (NP010) delivered the best effect on the retention and concentration of lignin in black liquor. Under the operation condition of $300 \mathrm{rpm}$ and $800 \mathrm{rpm}$, and transmembrane pressures of $0.5 \mathrm{bar}, 1 \mathrm{bar}, 1.5 \mathrm{bar}$, and $2 \mathrm{bar}$, the NP010 retention results are shown in Fig. 3.

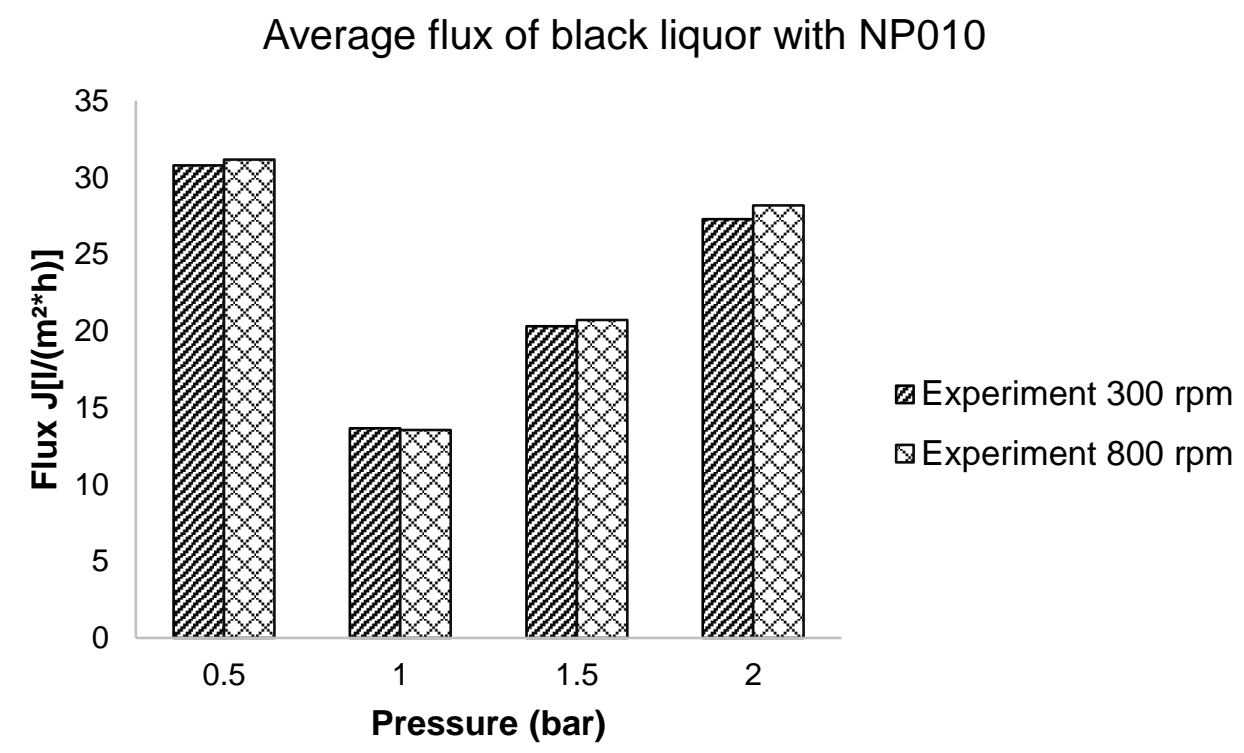

Fig. 3. Comparison of the average flux of nanofiltration membrane NP010 under different transmembrane pressures and different rotation speed

\section{ANALOGUE COMPUTATION}

\section{Theory Basis of Cross-flow Shearing}

The magnitude of the membrane flux is related to the transmembrane pressure, the filter cake filtration resistance $\left(R_{\mathrm{m}}\right)$, and the filtration resistance $\left(R_{\mathrm{c}}\right)$ of the original membrane, as shown in the basic equation of membrane filtration (Eq. 1). In this regard, how to reduce the filtration resistance of the filter cake is the core issue of increasing the membrane flux. This is shown as Eq. 1,

$$
\mathrm{q}_{\mathrm{s}}=\frac{\Delta \mathrm{p}}{\mu\left(\mathrm{R}_{\mathrm{m}}+\mathrm{R}_{\mathrm{c}}\right)}
$$

where $q_{\mathrm{s}}$ represents the flux $\left(\mathrm{L} /\left(\mathrm{m}^{2} \cdot \mathrm{h}\right)\right)$ of the nanofiltration membrane, $\Delta P$ represents the pressure $\left(\mathrm{N} / \mathrm{m}^{2}\right), \mu$ represents the viscosity $(\mathrm{kg} / \mathrm{s} \cdot \mathrm{m})$ of the liquid, $\underline{R}_{\mathrm{c}}$ represents the filtration resistance $\left(\mathrm{m}^{-1}\right)$ of the filter cake, and $R_{\mathrm{m}}$ represents the filtration resistance $\left(\mathrm{m}^{-1}\right)$ of the membrane. The formation of filter cake on the membrane surface is prevented by increasing the shearing stress on the membrane surface. According to the research conducted by Bouzerar et al. (2000) on the main characteristics of the internal flow field in this type of system, the local shearing stress exists on the fixed membrane under turbulent and laminar condition.

The local shearing stress for laminar flow: $\tau_{m l}=0.77 \rho v^{0.5}(\kappa \omega)^{1.5} r$

The local shearing stress for turbulent: $\tau_{m t}=0.0296 \rho v^{0.2}(\kappa \omega)^{1.8} r^{1.6}$ 
In this regard, the shearing stress on the membrane depends on the velocity coefficient $K, \omega(\mathrm{rpm})$, and the radial distance $(\mathrm{m})$.

\section{CFD Simulation Settings}

\section{Geometric modeling}

In the process of the modeling design of the blades and the filter chamber, a geometric three-dimensional graph of the filter chamber was modeled in strict accordance with the size of the blades and the filter chamber in the experimental equipment. The width of the filter chamber was $T=137 \mathrm{~mm}$, the thickness of the filter chamber was $H=30 \mathrm{~mm}$, the gap between the blade and the membrane was $C=15 \mathrm{~mm}$, the diameter of the rotating blade was $D=128 \mathrm{~mm}$, and the geometric three-dimensional graph of the filter chamber is shown in Fig. 4.

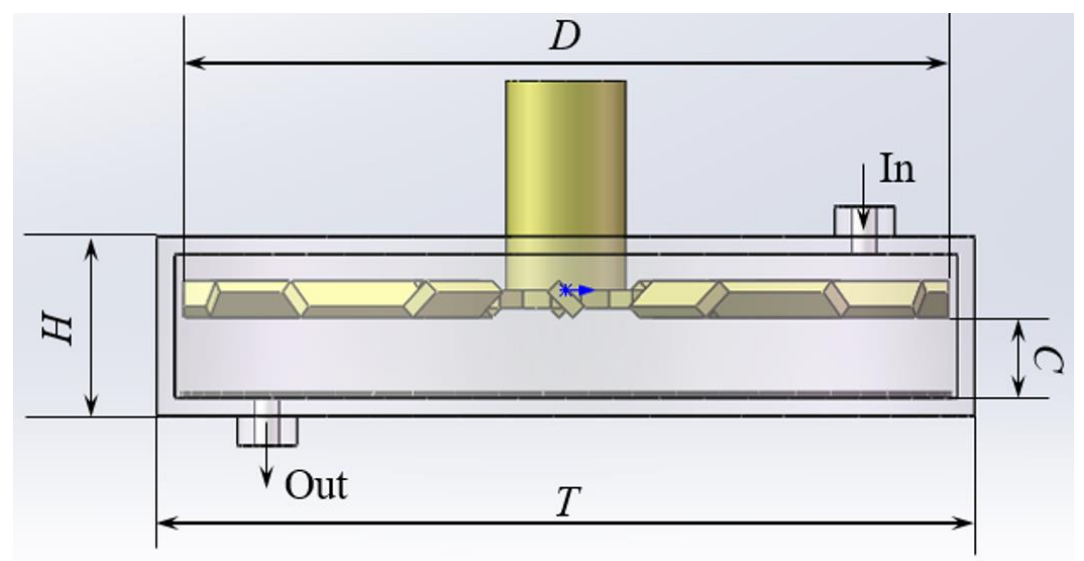

Fig. 4. Geometric three-dimensional graph of the filter chamber with SolidWorks

\section{Numerical modeling}

A three-dimensional (3D) model of the filter chamber and rotating blades was modeled in the Unigraphics NX (Siemens PLM Software, 8.5, Plano, TX, USA). Considering that the Markov random field (MRF) model was selected for computation in FLUENT (ANSYS, Inc., 16.0, Canonsburg, PA, USA), the model was partitioned as a whole and the process was completed in the NX. A cylindrical block was created in the filter chamber to enclose the blades as a moving area, while the filter chamber was filled with black liquid as a static area. In addition, a porous medium was established near the outlet of the filter chamber. The methods and steps of constructing the model are shown in Fig. 5.

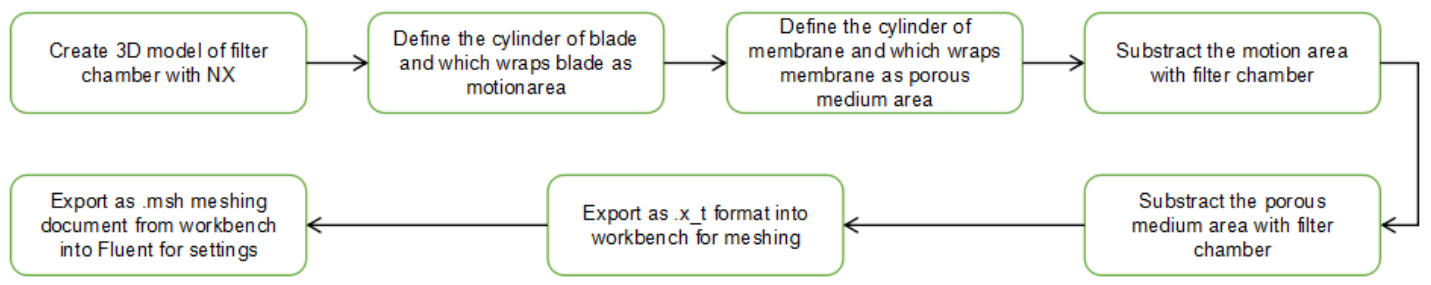

Fig. 5. Methods and steps for constructing numerical models 
The interior of the blade did not engage in the computation of the flow field and heat transfer was not taken into account. After the 3D model was created, it was imported into Workbench (ANSYS, Inc., 16.0, Canonsburg, PA, USA) for meshing, and the grids of the three areas were refined. A total of 817,211 grids were divided. The generated grids' quality was reviewed, the average grid quality was 0.82 , which indicated quality conformance. The grid model is shown in Fig. 6.

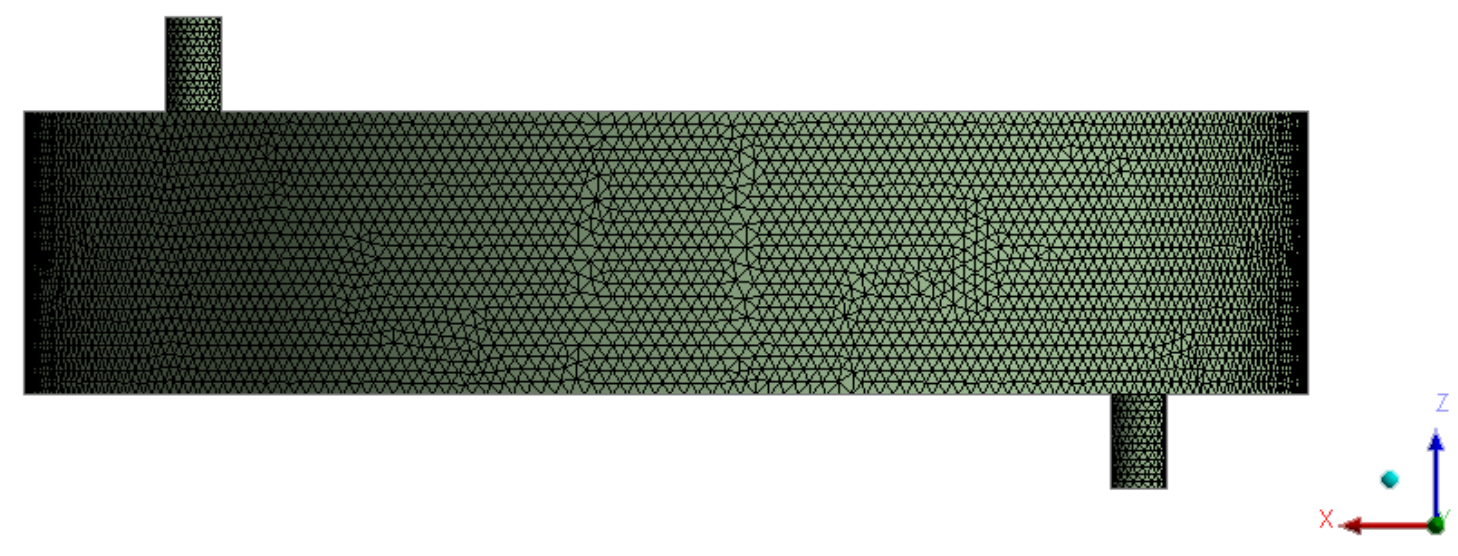

Fig. 6. Grid-based meshing of the overall filter chamber with Workbench

Setting of geometric boundary type

After the meshing was completed, the initial geometric boundary type of the model was set, that is, the corresponding physical meaning of geometric surface. As shown in Fig. 7, the side 'In' i a pressure inlet and 'Out' is a pressure outlet; it was correspondingly set as 'Pressure-Inlet' and 'Pressure-Outlet'. The remaining geometric boundary conditions are shown in the figure.

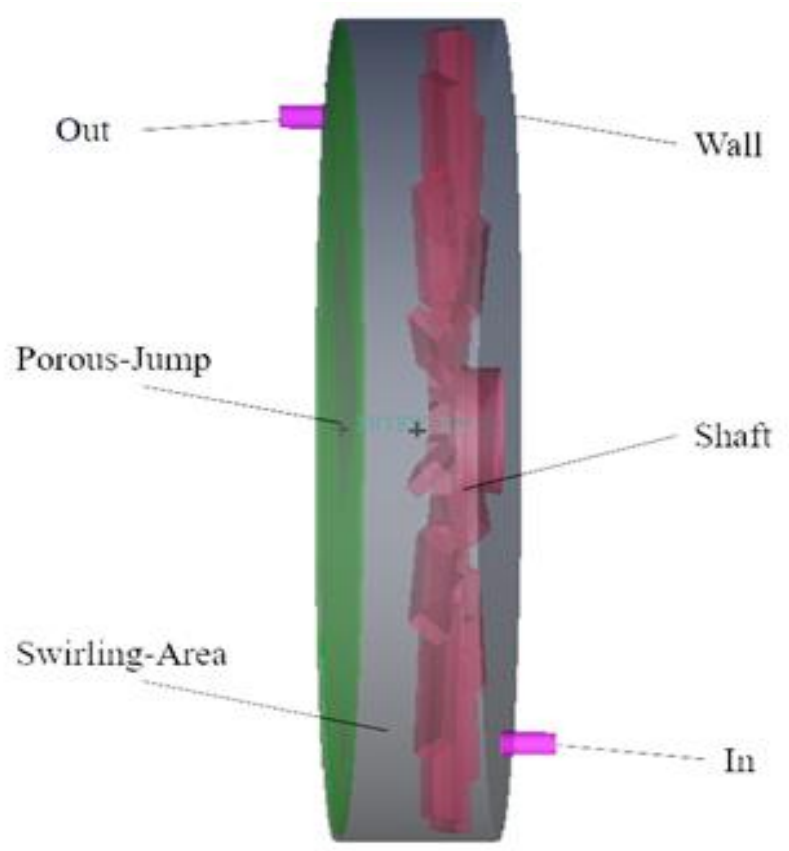

Fig. 7. Settings of geometric boundary type 


\section{Conditions for boundary setting}

Because the flow field in the chamber is complex, it was assumed that the fluid is constantly incompressible, and the flow process is isothermal. In this paper, the first-level filtering chamber was taken as the research object. The lignin content in black liquor is about $9 \%$ consistent with the experiment. The interaction force between the dual-phase liquid and solid was negligible. The shearing stress of the blade on the membrane surface was the research content. As such, single-phase fluid was taken as the flow medium in the chamber for flow field analysis. The radial pulsation of the filtrate after passing through the filter medium was negligible.

To ensure the authenticity and reliability of the numerical simulation of the research objects, each item in setting boundary conditions was directly quoted or indirectly calculated based on the experimental data. The pressure-base implicit solution method was adopted, the k-epsilon RNG under the turbulence model was selected, and the standard wall function was used for near-wall treatment. The physical properties of the fluid include the density $\left(1098 \mathrm{~kg} / \mathrm{m}^{3}\right)$ and viscosity $(5.85 \mathrm{~Pa} \cdot \mathrm{s})$ of the black liquor and the rpm of the rotor was set at $300 \mathrm{rpm}$ and $800 \mathrm{rpm}$, respectively. The inlet boundaries of the filter chamber were set as pressure inlets, which are 0.5 bar, 1 bar, 1.5 bar, and 2 bar, respectively. The centrifugal force generated by the high-speed rotation of the blade was much greater than gravity, so the effect of gravity was not considered here. The outlet pressure of filtrate was set at 0 bar.

Due to the presence of membranes in the flow field, porous media conditions are required to set the boundary to enhance the calculation accuracy. The momentum equation of the porous medium model is adding the source term to the standard momentum equation, and the source term includes the viscosity loss term and the inertial loss term:

$$
S_{i}=\left(\frac{\mu}{\alpha} v_{i}+C_{2} \frac{1}{2} \rho|v| v_{i}\right)
$$

In the equation: $S_{i}$ is the source of the momentum equation; $|v|$ is the speed; $\alpha$ is the permeability coefficient, and $C_{2}$ is the inertial resistance coefficient. That is, the two matrices are simplified to diagonal matrices, with coefficients on the diagonals being $\alpha$ and $C_{2}$, and elements other than diagonals being 0 , and the porous jump parameters including face permeability, porous medium thickness, and pressure coefficient are defined as follows,

$$
\begin{aligned}
& u=B \frac{\Delta \mathrm{P}}{\mu \times L} \\
& \mathrm{C}_{2}=\frac{1}{\mathrm{C}^{2}} \frac{\left[\mathrm{A}_{\mathrm{p}} / \mathrm{A}_{\mathrm{f}}\right]^{2}-1}{\mathrm{~L}}
\end{aligned}
$$

where $u$ represents the speed $(\mathrm{m} / \mathrm{s})$ of the liquid passing through the filter layer, $B$ represents the permeability $\left(\mathrm{m}^{2}\right)$ of the filter medium, $L$ represents the filter medium thickness $(\mathrm{m})$, $\triangle P$ represents the transmembrane pressure difference, and $\mu$ represents the viscosity $(\mathrm{Pa} \cdot \mathrm{s})$ of black liquor. A high $B$ value means that the liquid is easy to pass through the medium. The smaller the value, the greater the resistance of the medium. In this analysis, $C=0.98$, representing the porosity of the filter medium. 


\section{RESULTS AND DISCUSSION}

The simulated results mainly observe the changes in the tangential velocity field on membrane surface and the blade dynamic pressure under different rotation speed and the comparison in flux of experimental and simulated results.

\section{Velocity Field Variation of Nanofiltration Membrane}

Due to the shearing action of the blade on the black liquor and the variation in the velocity field on the nanofiltration membrane, the surface is related to the blade rotation rate. The cloud diagrams of the tangential velocity field on the membrane surface at 800 rpm and $300 \mathrm{rpm}$ are shown in Figs. 8 and 9. The variation of tangential velocity with the membrane radius is shown in Figs. 10 and 11. The tangential velocity on the membrane surface gradually increased with the radius. At $300 \mathrm{rpm}$, the tangential velocity on the membrane gradually increased to $1.4 \mathrm{~m} / \mathrm{s}$ in the radial direction of the membrane. At 800 $\mathrm{rpm}$, the variation trends and trajectories of tangential velocity on the membrane with the transmembrane pressure of 0.5 bar, 1 bar, $1.5 \mathrm{bar}$, and 2 bar were similar. The tangential velocity on the membrane surface gradually increased to $4 \mathrm{~m} / \mathrm{s}$ in the radial direction of the membrane, which was 3 times the tangential velocity at $300 \mathrm{rpm}$.

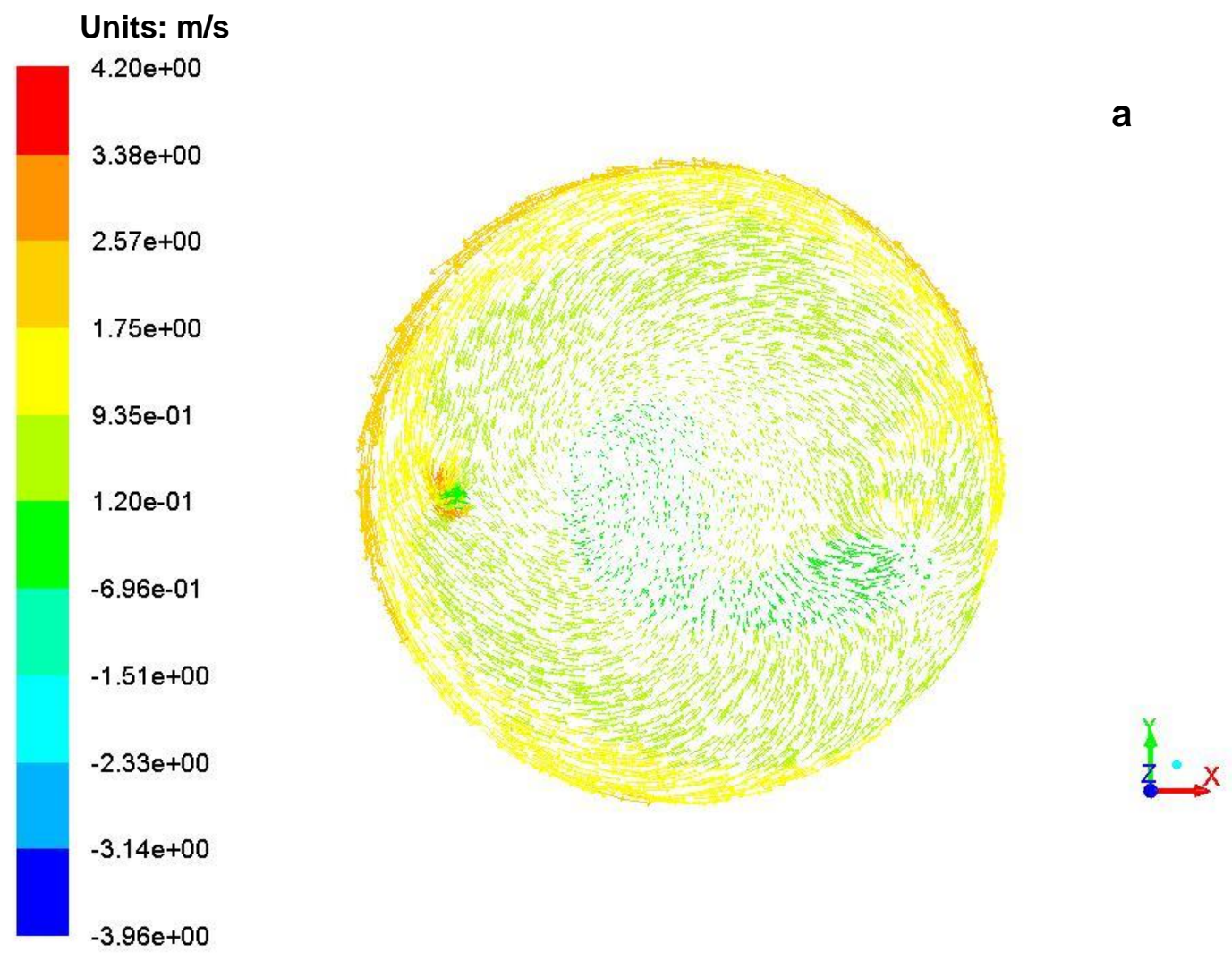




\section{Units: $\mathbf{m} / \mathbf{s}$}

$8.34 \mathrm{e}+00$
$6.75 \mathrm{e}+00$
$5.16 \mathrm{e}+00$
$3.57 \mathrm{e}+00$
$1.98 \mathrm{e}+00$
$3.90 \mathrm{e}-01$
$-1.20 \mathrm{e}+00$
$-2.79 \mathrm{e}+00$
$-4.38 \mathrm{e}+00$
$-5.97 \mathrm{e}+00$
$-7.56 \mathrm{e}+00$

b

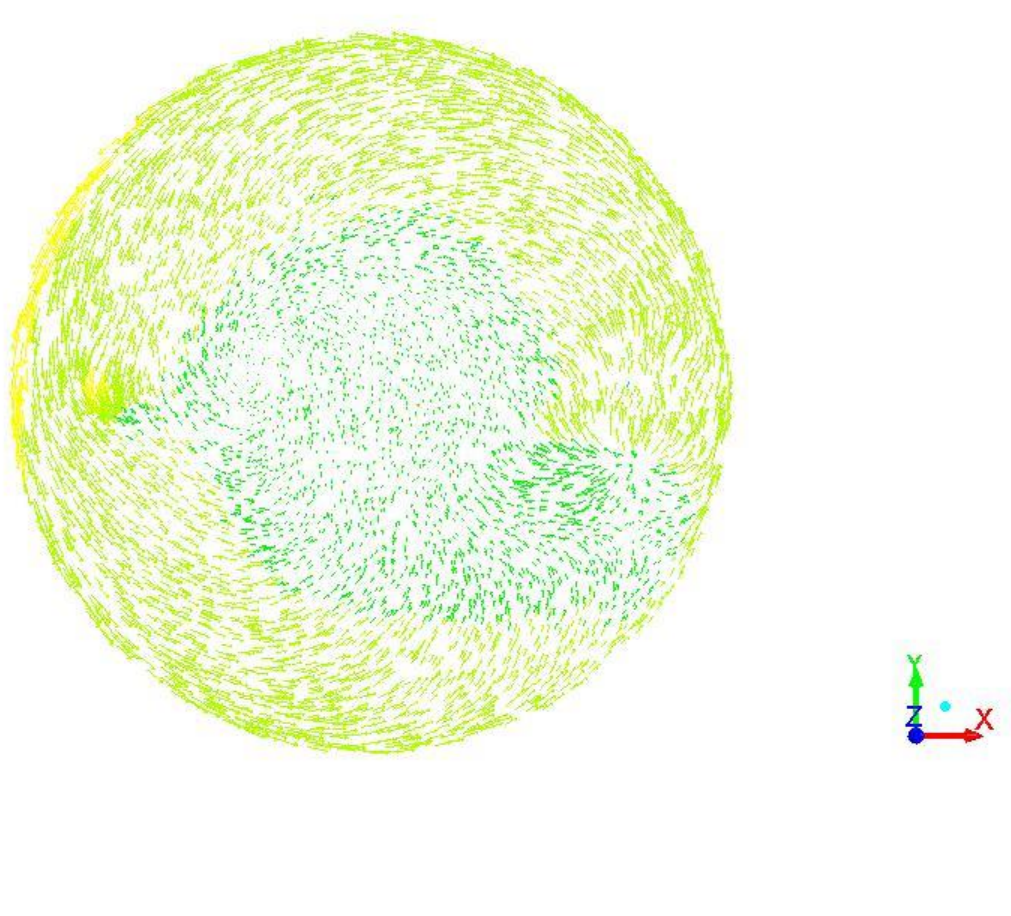

Units: $\mathbf{m} / \mathbf{s}$

$7.40 \mathrm{e}+00$

$5.92 e+00$

$4.45 e+00$

$2.97 e+00$

$1.49 e+00$

$1.96 \mathrm{e}-02$

$-1.46 e+00$

$-2.93 e+00$

$-4.41 e+00$

$-5.88 e+00$

$-7.36 e+00$

C

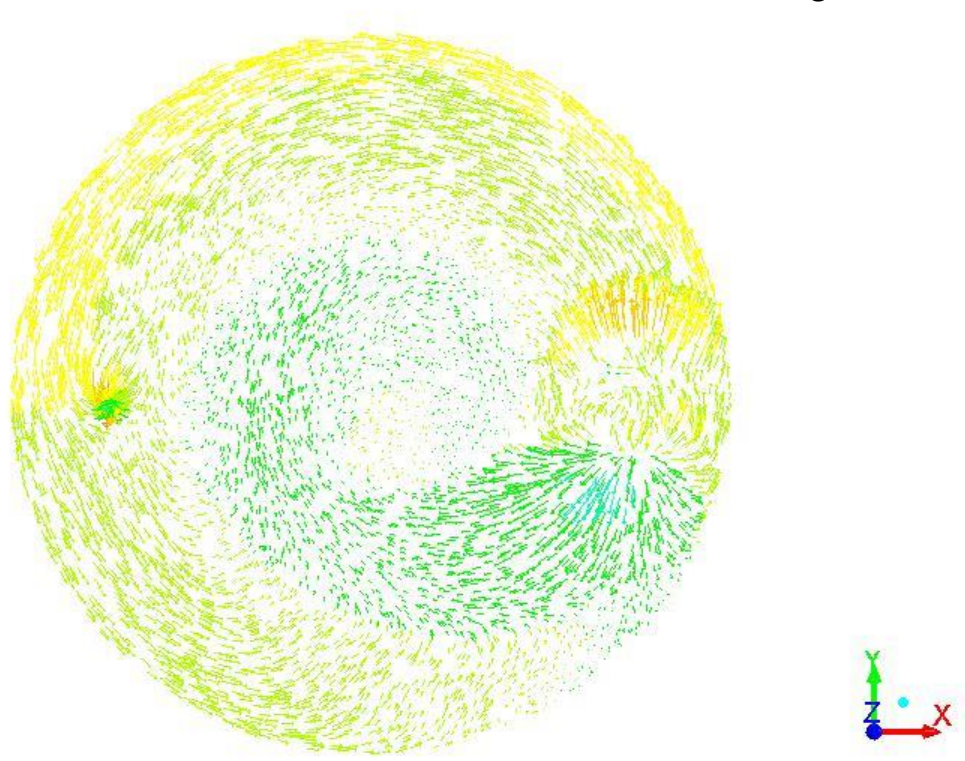




\section{Units: $\mathbf{m} / \mathbf{s}$}

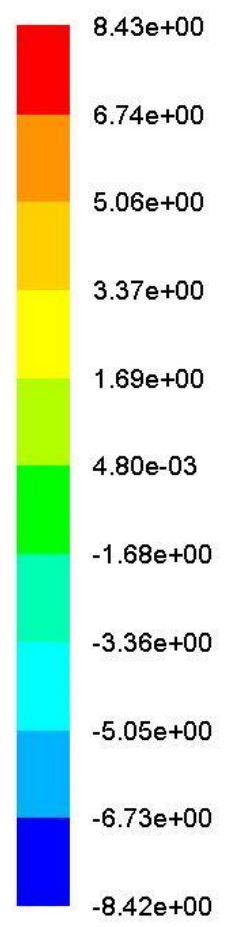

d
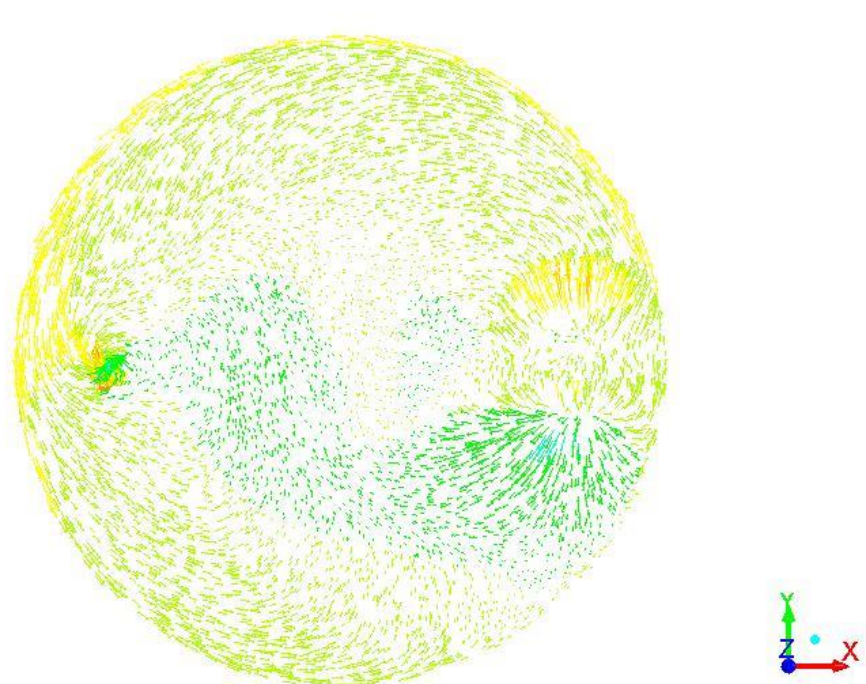

Fig. 8. Cloud diagram of shearing velocity on the membrane surface at $300 \mathrm{rpm}: \mathrm{a}=0.5 \mathrm{bar}, \mathrm{b}=$ 1 bar, $c=1.5$ bar, and $d=2$ bar

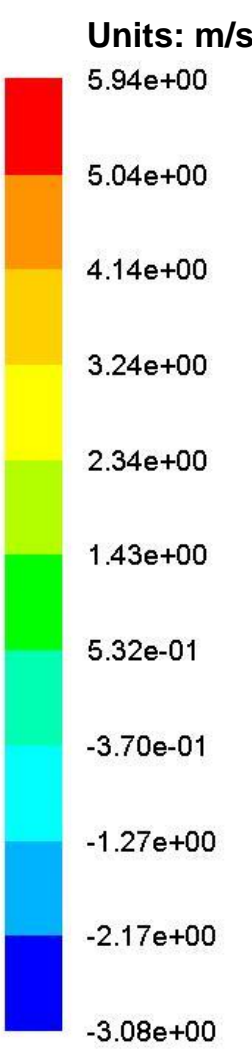


Units: $\mathbf{m} / \mathbf{s}$

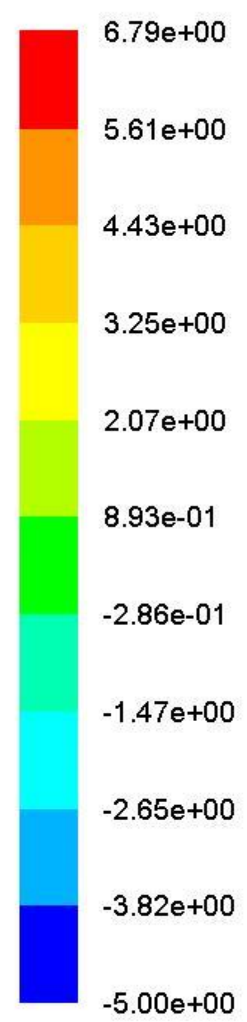

b
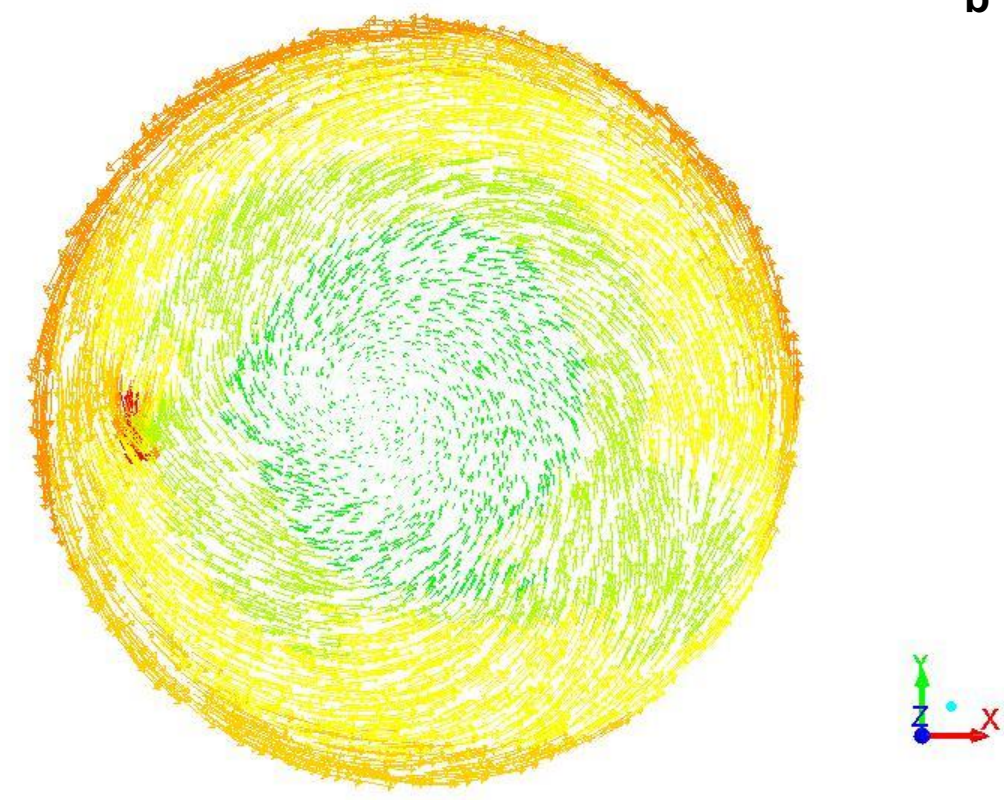

Units: $\mathbf{m} / \mathbf{s}$

$8.56 \mathrm{e}+00$

$6.92 e+00$

$5.28 \mathrm{e}+00$

$3.65 \mathrm{e}+00$

$2.01 e+00$

$3.72 \mathrm{e}-01$

$-1.27 e+00$

$-2.90 e+00$

$-4.54 \mathrm{e}+00$

$-6.18 e+00$

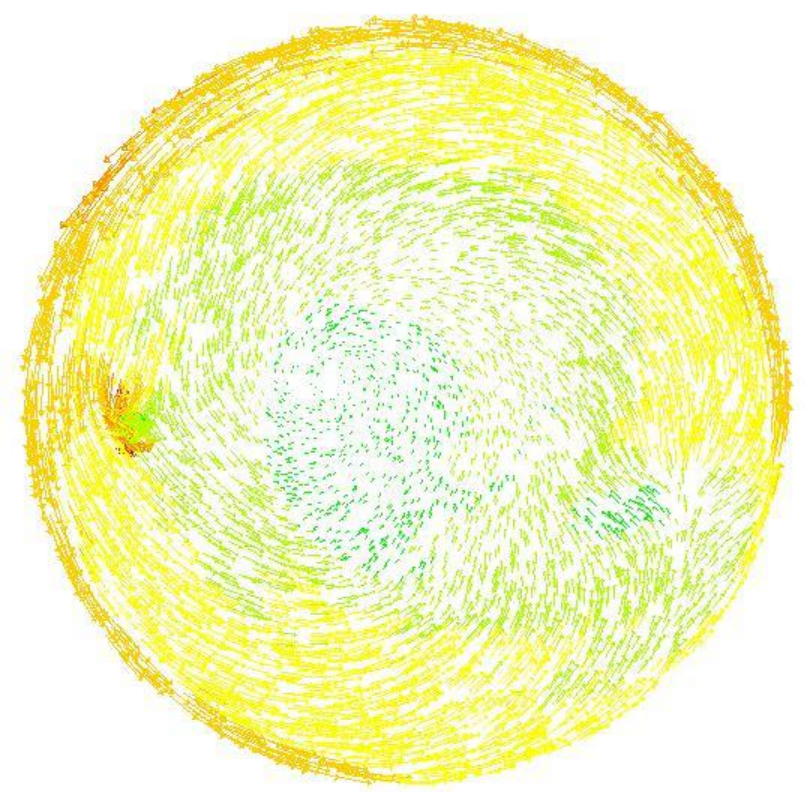

C

$-7.81 e+00$ 


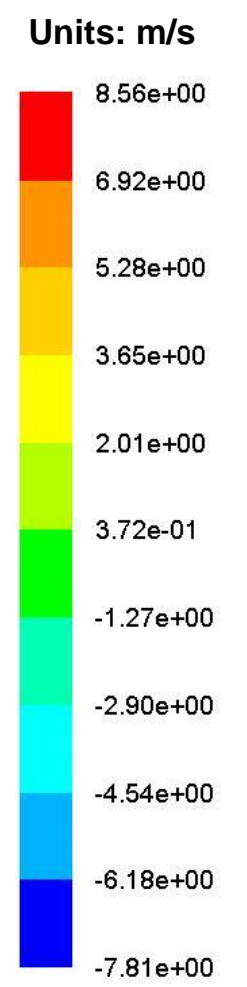

d

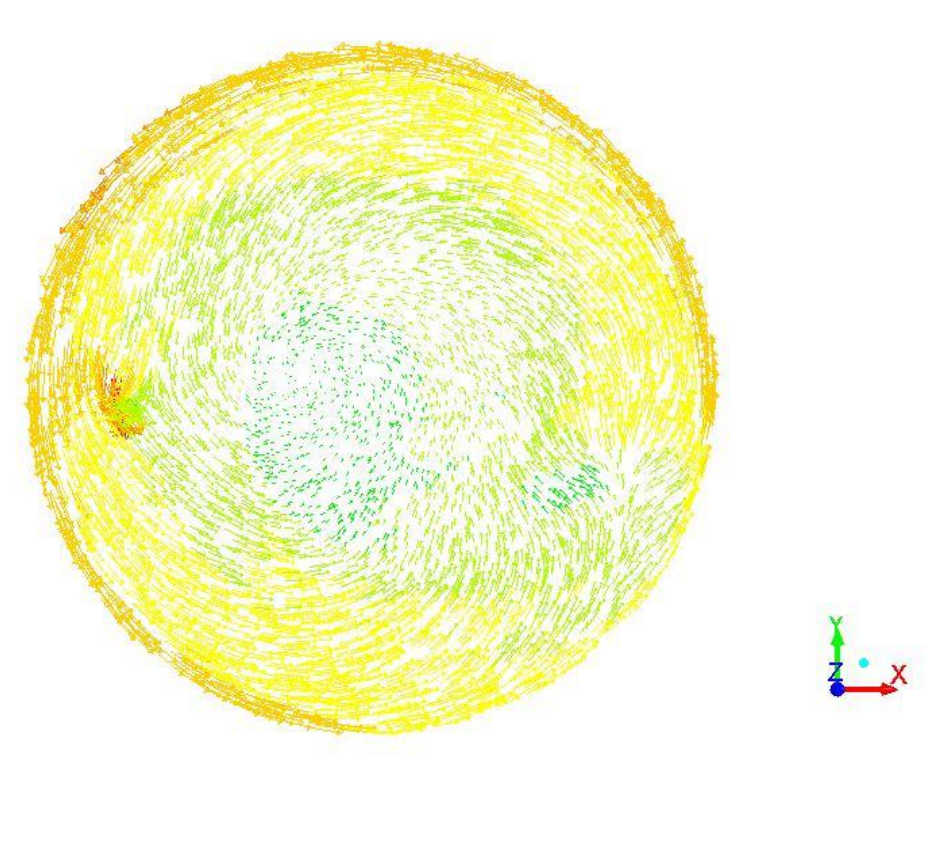

Fig. 9. Cloud diagram of shearing velocity on the membrane surface at $800 \mathrm{rpm}: \mathrm{a}=0.5 \mathrm{bar}, \mathrm{b}=$ 1 bar, $\mathrm{c}=1.5$ bar, and $\mathrm{d}=2$ bar

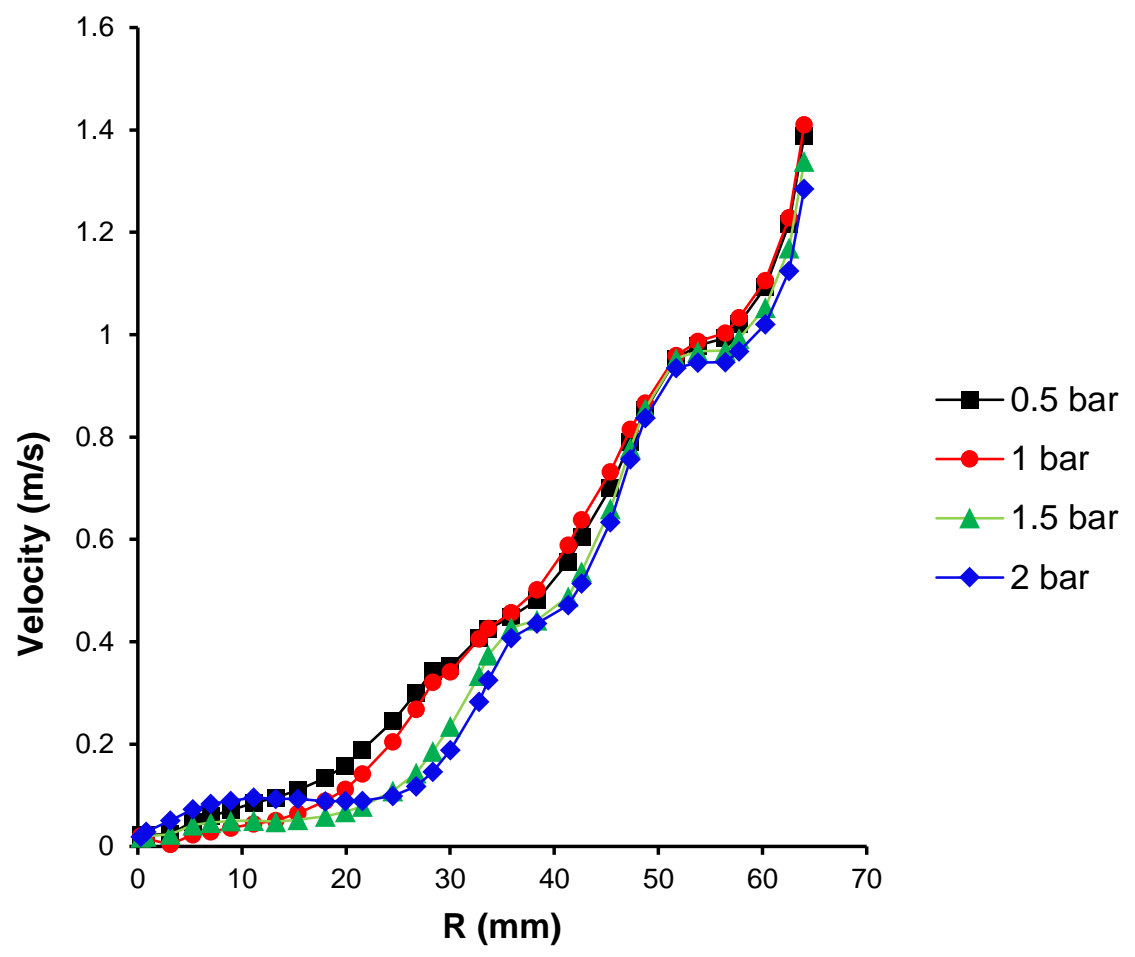

Fig. 10. The tangential velocity on the membrane surface at $300 \mathrm{rpm}$ variation with the radius of the filter membrane 


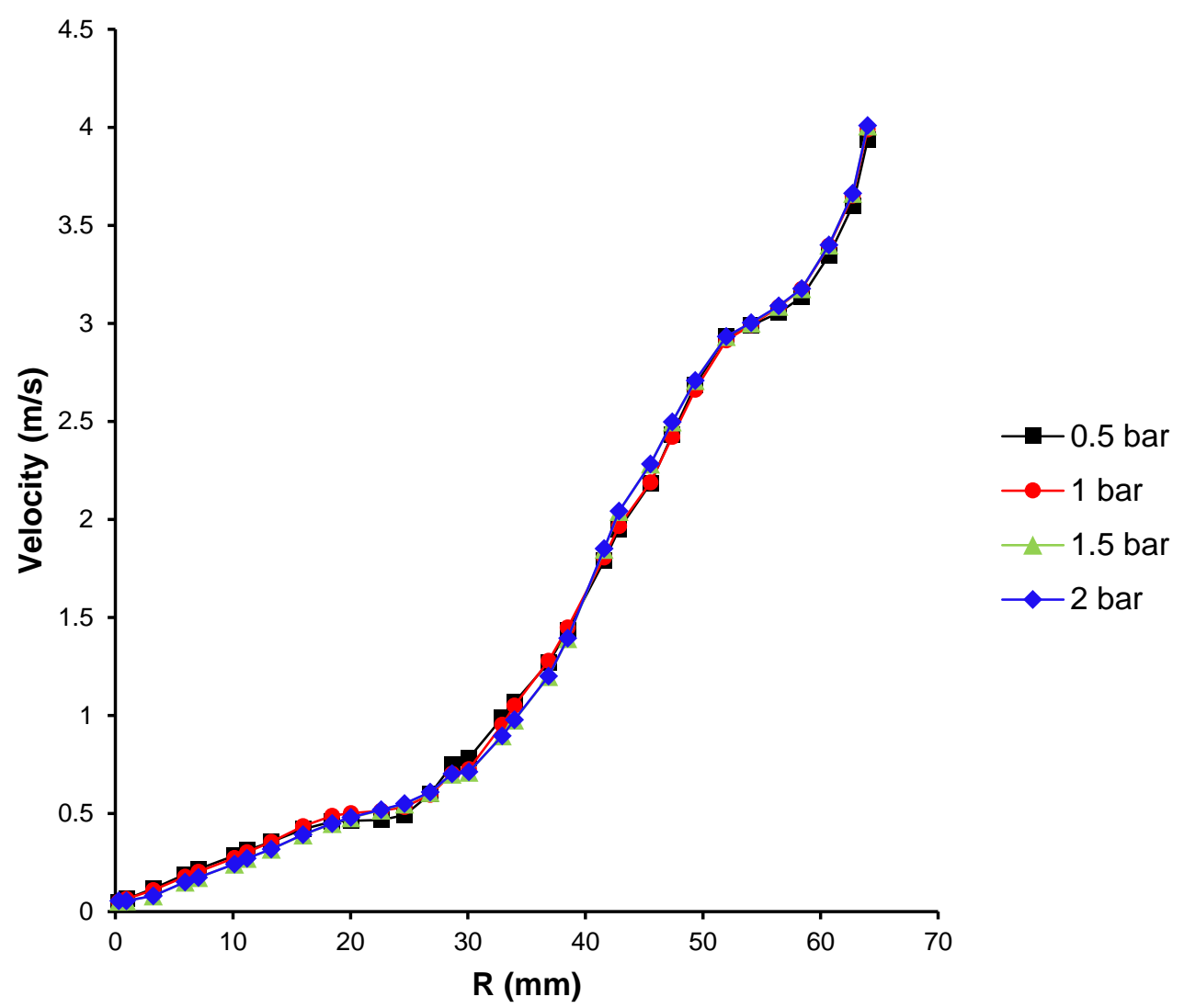

Fig. 11. The tangential velocity on the membrane surface at $800 \mathrm{rpm}$ variation with the radius of the filter membrane

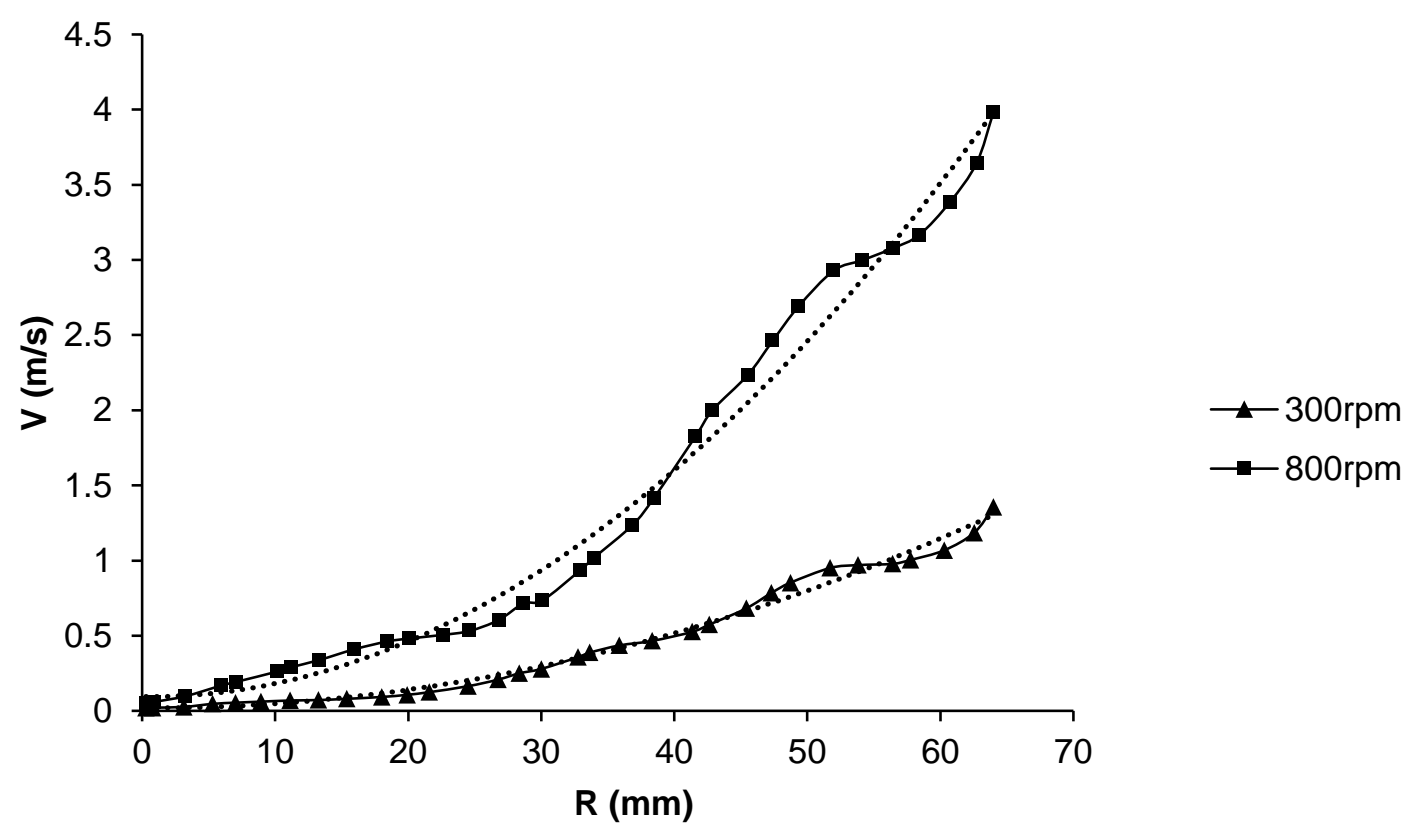

Fig. 12. Tangential flow velocity regression line on membrane surface at $300 \mathrm{rpm}$ and $800 \mathrm{rpm}$ 
By comparing the cloud diagram of tangential velocity on the membrane surface in Figure 8 and 9, it can be seen that the tangential velocity at $800 \mathrm{rpm}$ was significantly higher than that at $300 \mathrm{rpm}$. According to formula 3, it can be concluded that at $800 \mathrm{rpm}$, the shearing force generated by the blades on the membrane surface was higher than that at $300 \mathrm{rpm}$. That is, compared with $300 \mathrm{rpm}$, the filtered flux of black liquid was higher at $800 \mathrm{rpm}$. According to the experiment results of average filtered flux in Fig. 3, the filtered flux at $800 \mathrm{rpm}$ was slightly higher than that at $300 \mathrm{rpm}$, with slight differences. The change curve of tangential flow velocity in Figs. 10 and 11 was linearly regressed, and a tangential flow velocity regression line on the membrane surface at 300 and $800 \mathrm{rpm}$ was obtained. The relationship between the membrane radius and the tangential flow velocity were thus obtained. The tangential flow velocity on any position on the membrane surface can be calculated by the trend line in Fig. 12.

\section{Blade Pressure Variation}

The rotating blade in the dynamic cross-flow filtration chamber conducts shearing action on the black liquor, which causes the black liquor to exert pressure on the rotating blades. The pressure variations are shown in Figs. 13 and 14. Because the pressure variation is caused by the pressure of the black liquor on the blade due to the blade rotation, this paper presents the variation trend of dynamic pressure with blade radius as shown in Figs. 15 and 16. The dynamic pressure of the blade increased with the radius and reached the maximum at the outer edge of the blade. At $300 \mathrm{rpm}$ and when the membrane pressure was 1 bar, the maximum dynamic pressure reached $1300 \mathrm{~Pa}$; at $300 \mathrm{rpm}$ and when the membrane pressure was 2 bar, and the minimum value of maximum dynamic pressure was $1100 \mathrm{~Pa}$. At $800 \mathrm{rpm}$ and when the transmembrane pressure was $0.5 \mathrm{bar}, 1 \mathrm{bar}, 1.5 \mathrm{bar}$, and 2 bar, the variation trajectories and trends of blade pressure were similar. The maximum dynamic pressure was approximately $9000 \mathrm{~Pa}$, which was 7 times the maximum pressure on the blade at $300 \mathrm{rpm}$. According to Figs. 13 through 16, it can be seen that the rpm had an effect on the pressure of the blade, while the transmembrane pressure difference had little effect on the pressure of the blade.

\section{Comparison of Flux Results}

According to the experimental and simulation results of capturing pulping black liquor by the blade cross-flow nanofiltration membrane, the average filtered flux of black liquor is the most ideal when the transmembrane pressure is 0.5 bar, as shown in Fig. 17. The flux change is basically the same as the experiment obtained in the simulation, and the comparison result verifies the simulation model of blade dynamic cross-flow, which shows that the simulation model is accurate.

According to the simulation results of the pressure on the blades, the pressure on the blades at $800 \mathrm{rpm}$ is 7 times that at $300 \mathrm{rpm}$. According to the simulation results of the tangential flow velocity of the membrane surface, the tangential flow velocity of the blades at $800 \mathrm{rpm}$ is 3 times that at $300 \mathrm{rpm}$. It can be seen from Fig. 17 that the filtered flux of black liquid was not much different between $300 \mathrm{rpm}$ and $800 \mathrm{rpm}$. According to the above experiments and simulation results, when the blade dynamic cross-flow uses $1 \mathrm{kDa}$ nanofiltration membrane to filter black liquor, the average filtered flux of black liquor was not much different between $800 \mathrm{rpm}$ and $300 \mathrm{rpm}$. The filtration process at $800 \mathrm{rpm}$ consumes more energy, and the blade is under more pressure, thus shortening the service life. 
Units: Pa

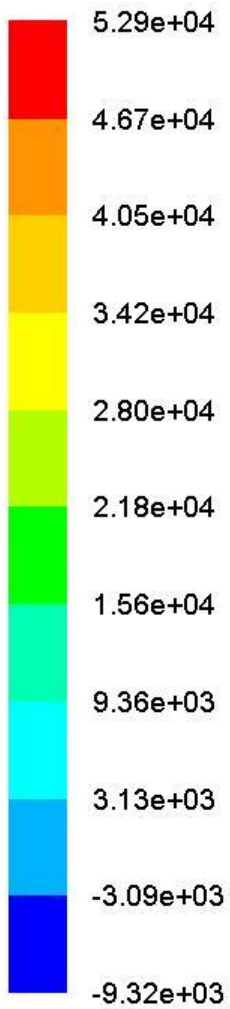

Units: Pa

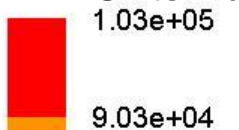

$9.03 e+04$

$7.75 \mathrm{e}+04$

$6.47 e+04$

$5.19 e+04$

$3.91 e+04$

$2.63 e+04$

$1.36 e+04$

$7.67 e+02$

$-1.20 e+04$

$-2.48 e+04$ a
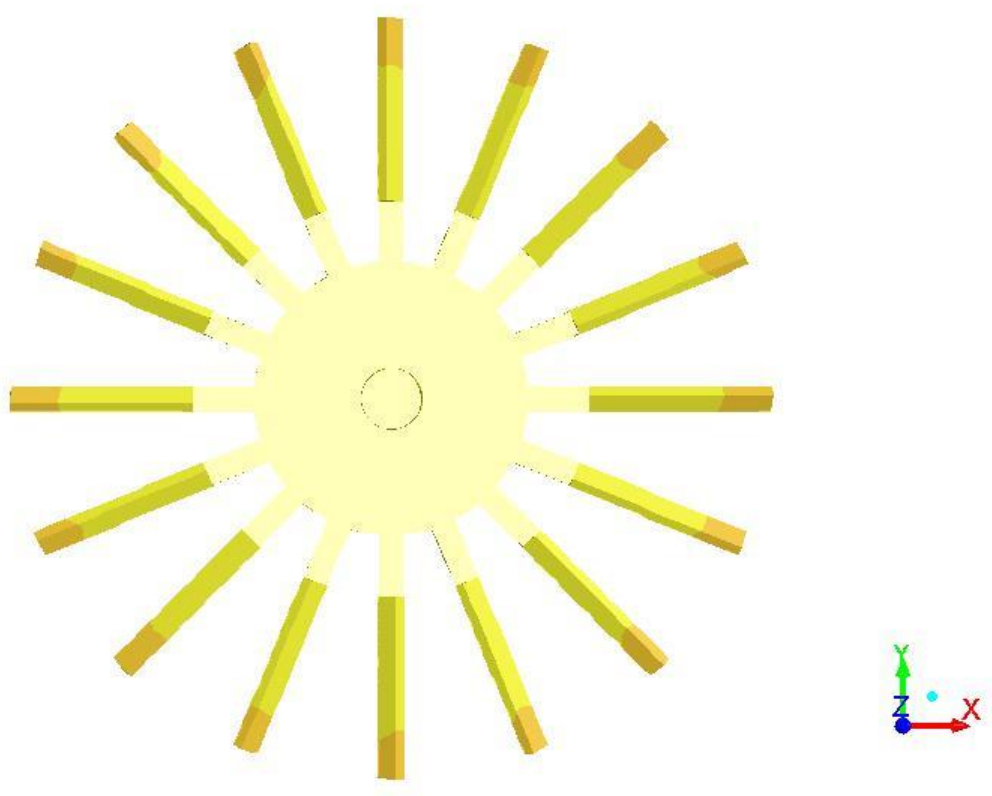

b
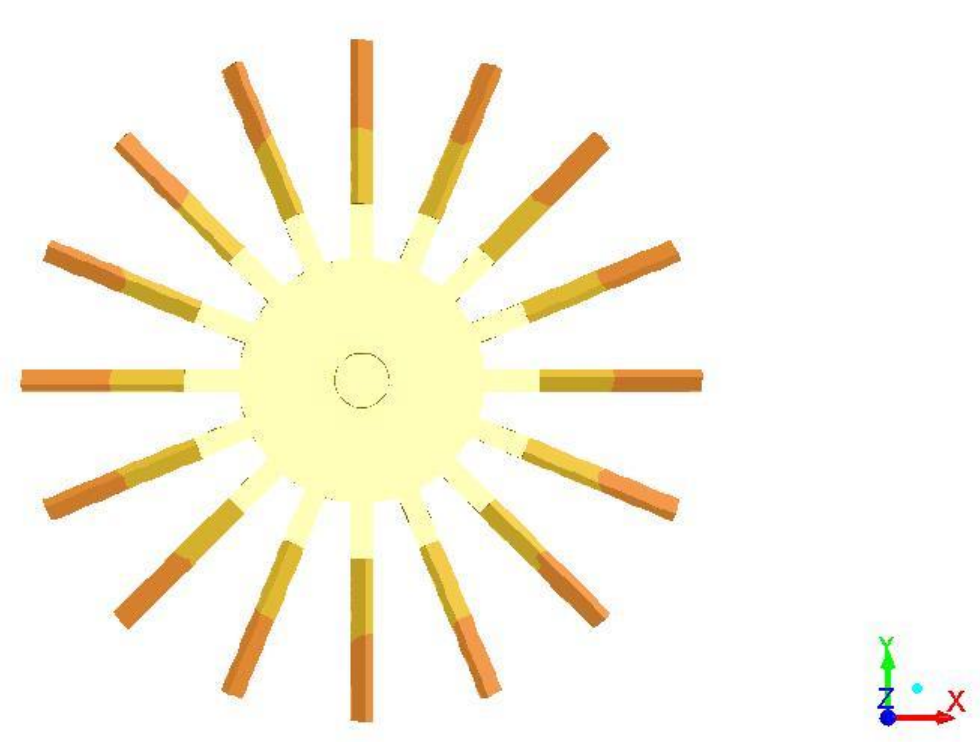


\section{Units: Pa \\ $1.54 \mathrm{e}+05$ \\ $1.37 \mathrm{e}+05$ \\ $1.20 \mathrm{e}+05$ \\ $1.03 e+05$ \\ $8.62 e+04$ \\ $6.92 e+04$ \\ $5.22 e+04$ \\ $3.52 e+04$ \\ $1.82 e+04$ \\ $1.23 e+03$ \\ $-1.58 \mathrm{e}+04$}

Units: Pa
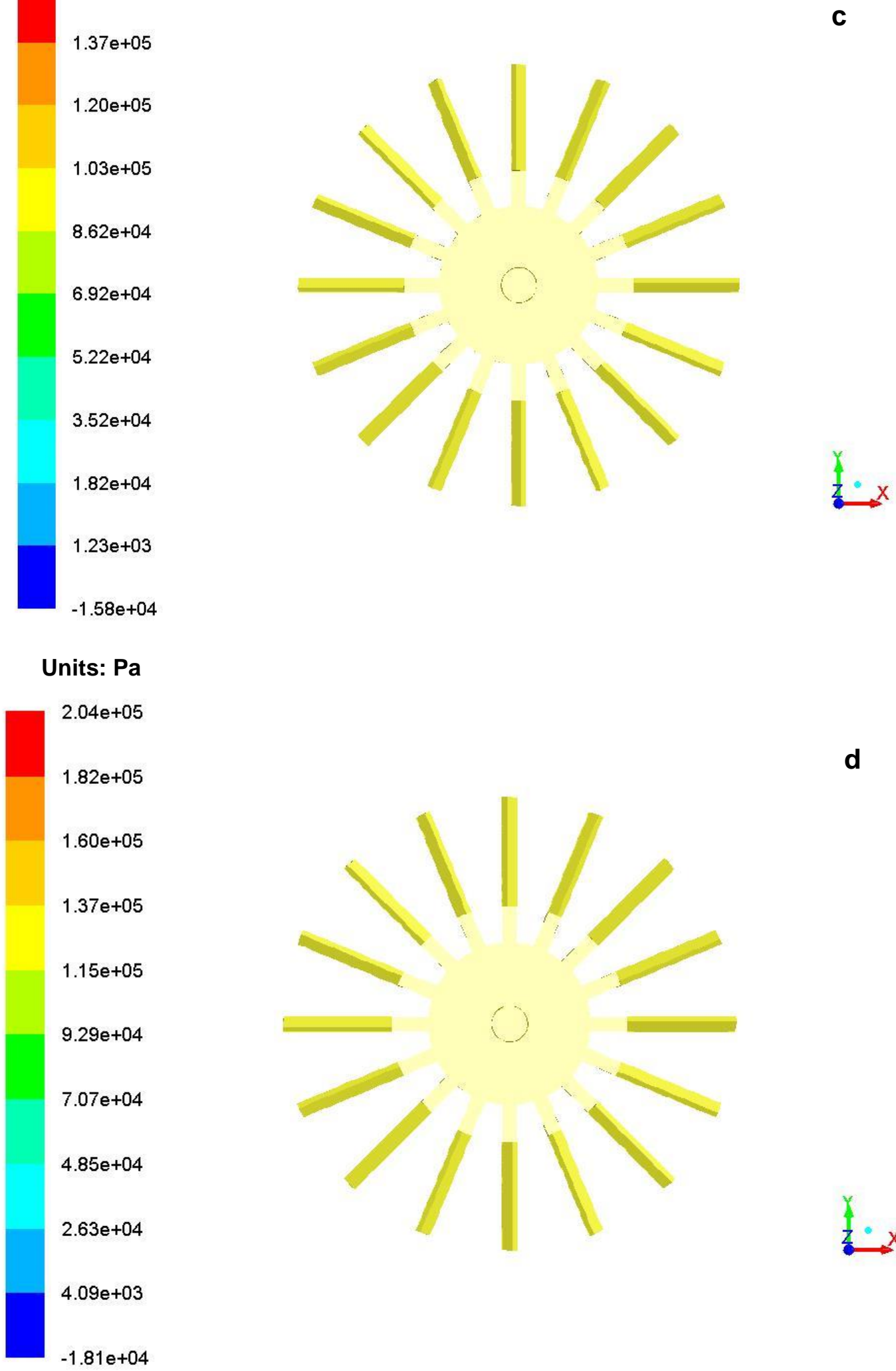

d
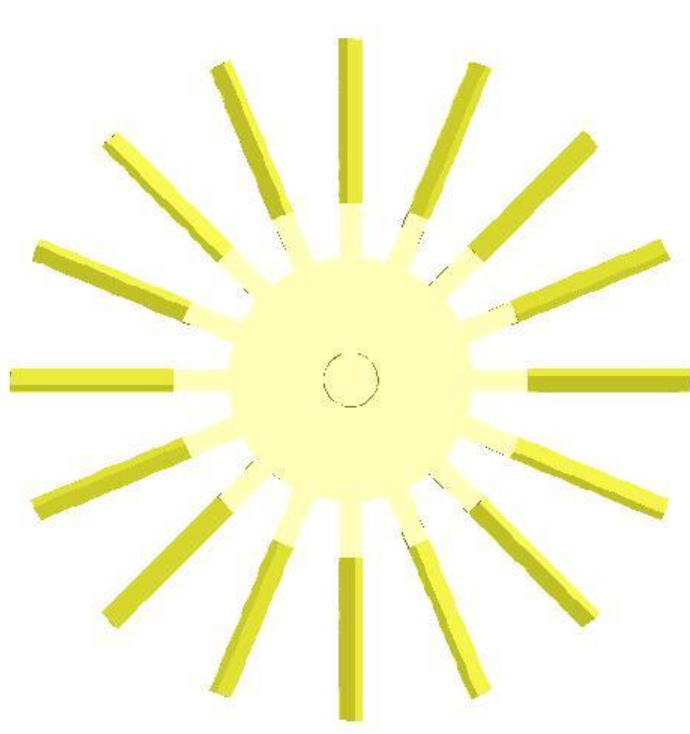

Fig. 13. Cloud diagram of blade pressure change at $300 \mathrm{rpm}: \mathrm{a}=0.5 \mathrm{bar}, \mathrm{b}=1 \mathrm{bar}, \mathrm{c}=1.5 \mathrm{bar}$, and $d=2$ bar 


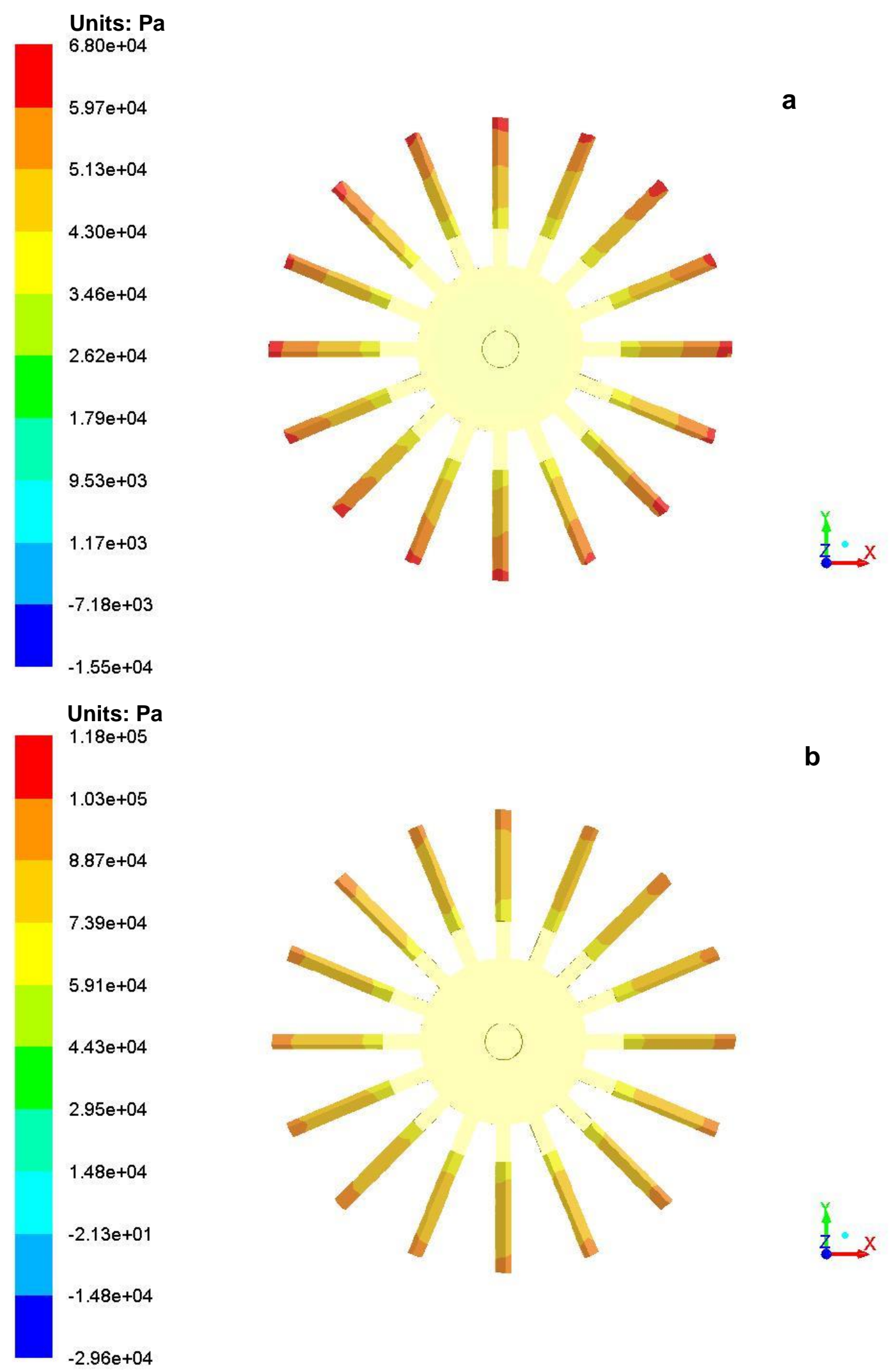




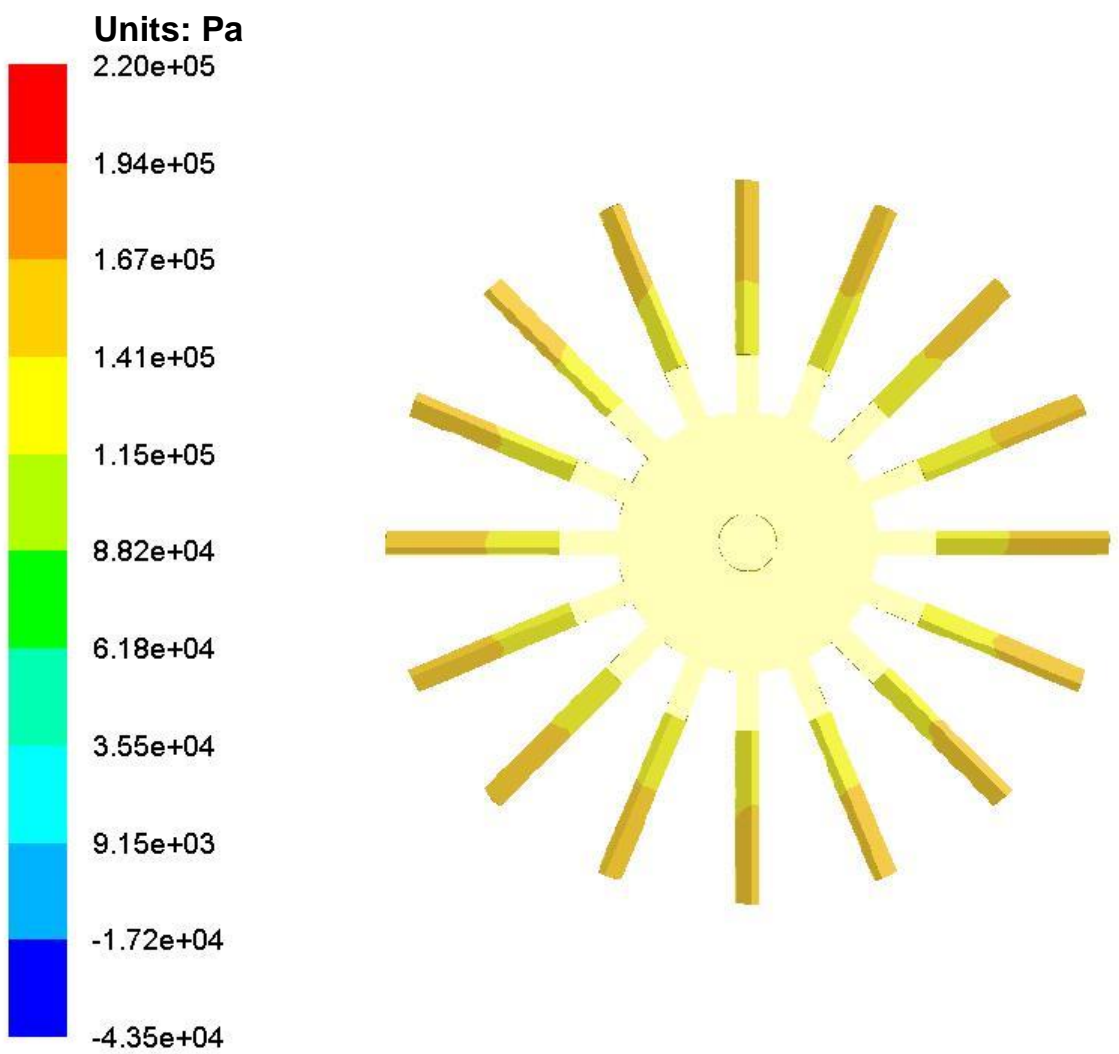

C

$-4.35 e+04$

Units: Pa

$2.20 \mathrm{e}+05$

d

$1.94 \mathrm{e}+05$

$1.67 \mathrm{e}+05$

$1.41 \mathrm{e}+05$

$1.15 e+05$

$8.82 e+04$

$6.18 \mathrm{e}+04$

$3.55 e+04$

$9.16 e+03$

$-1.72 e+04$
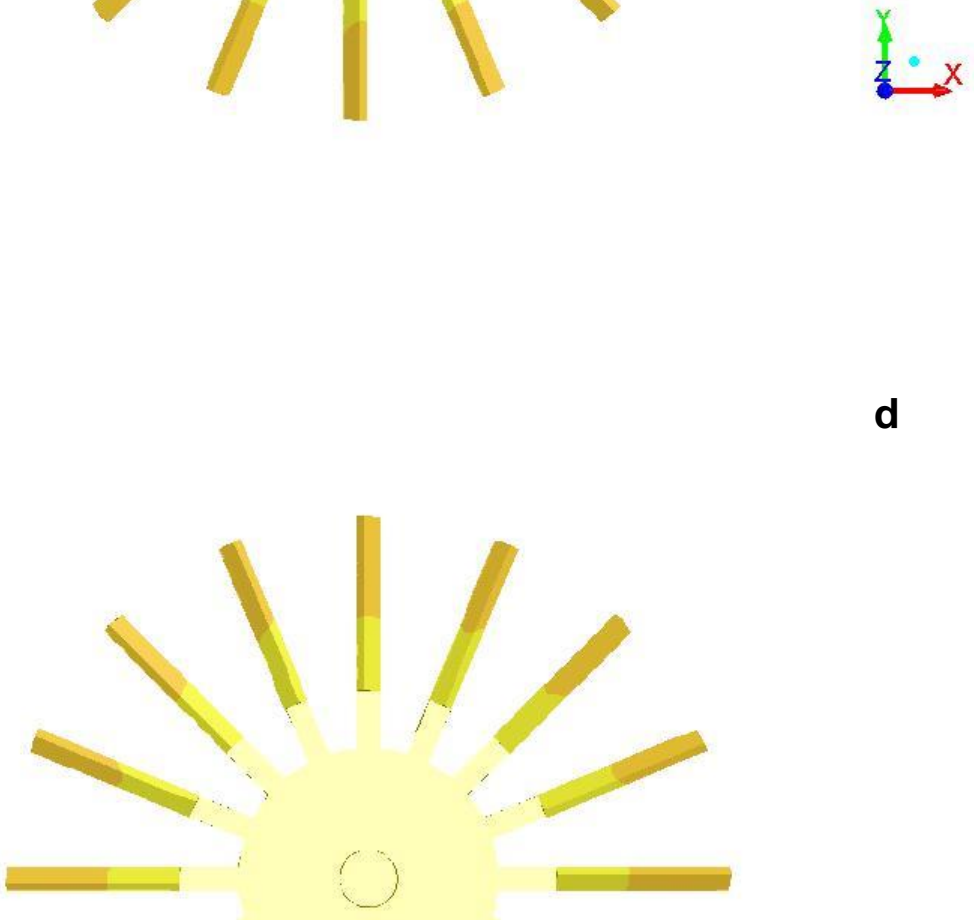

$-4.35 e+04$
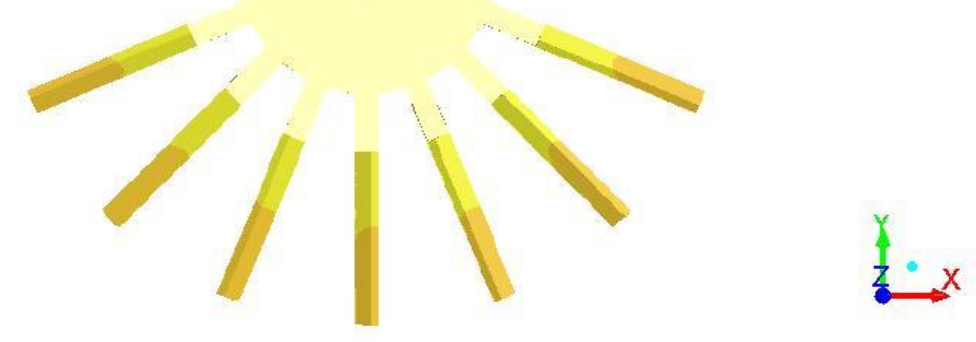

Fig. 14. Cloud diagram of blade pressure variation at $800 \mathrm{rpm}: \mathrm{a}=0.5 \mathrm{bar}, \mathrm{b}=1 \mathrm{bar}, \mathrm{c}=1.5 \mathrm{bar}$, and $d=2$ bar 


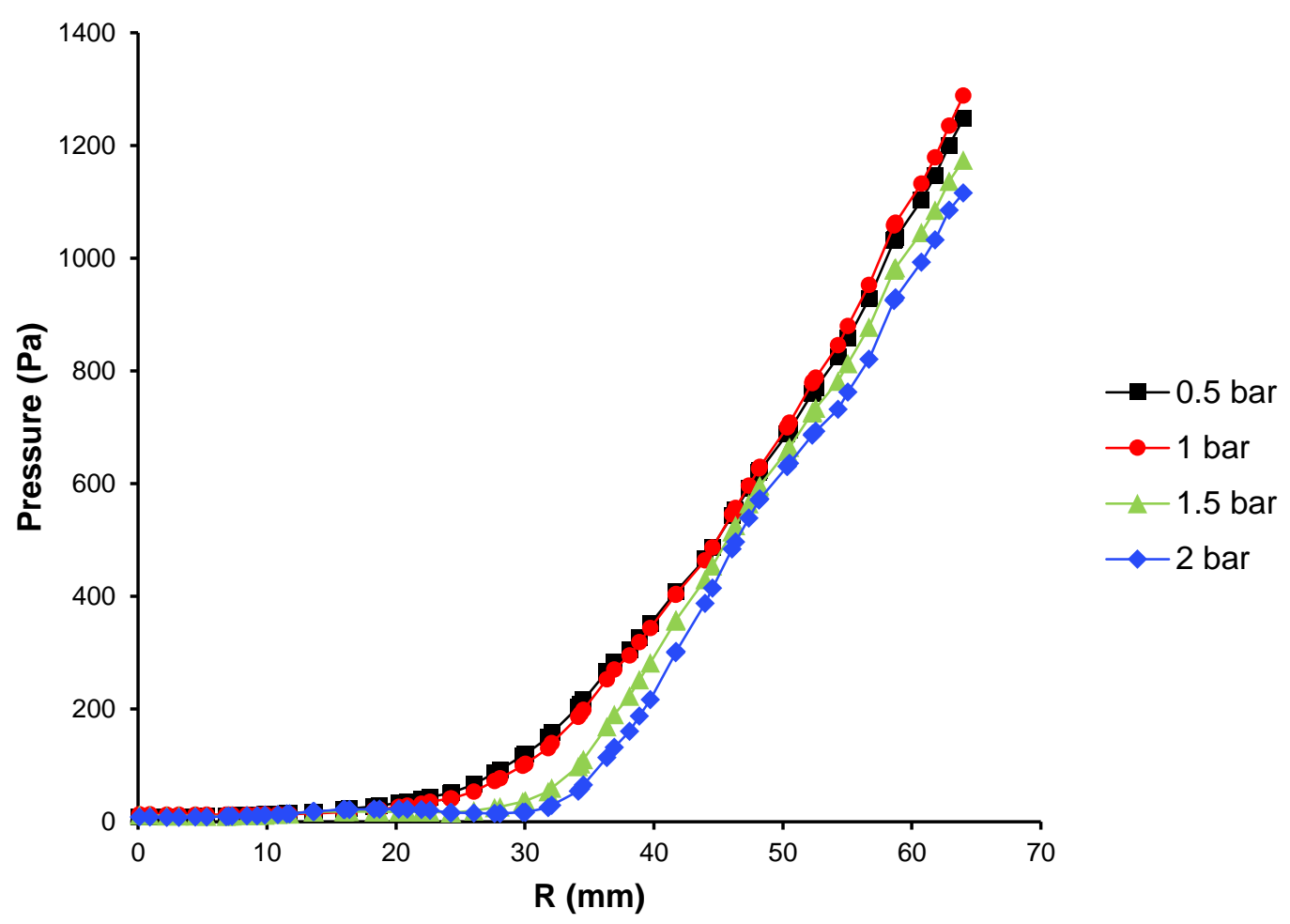

Fig. 15. Variation of blade dynamic pressure with radius at $300 \mathrm{rpm}$

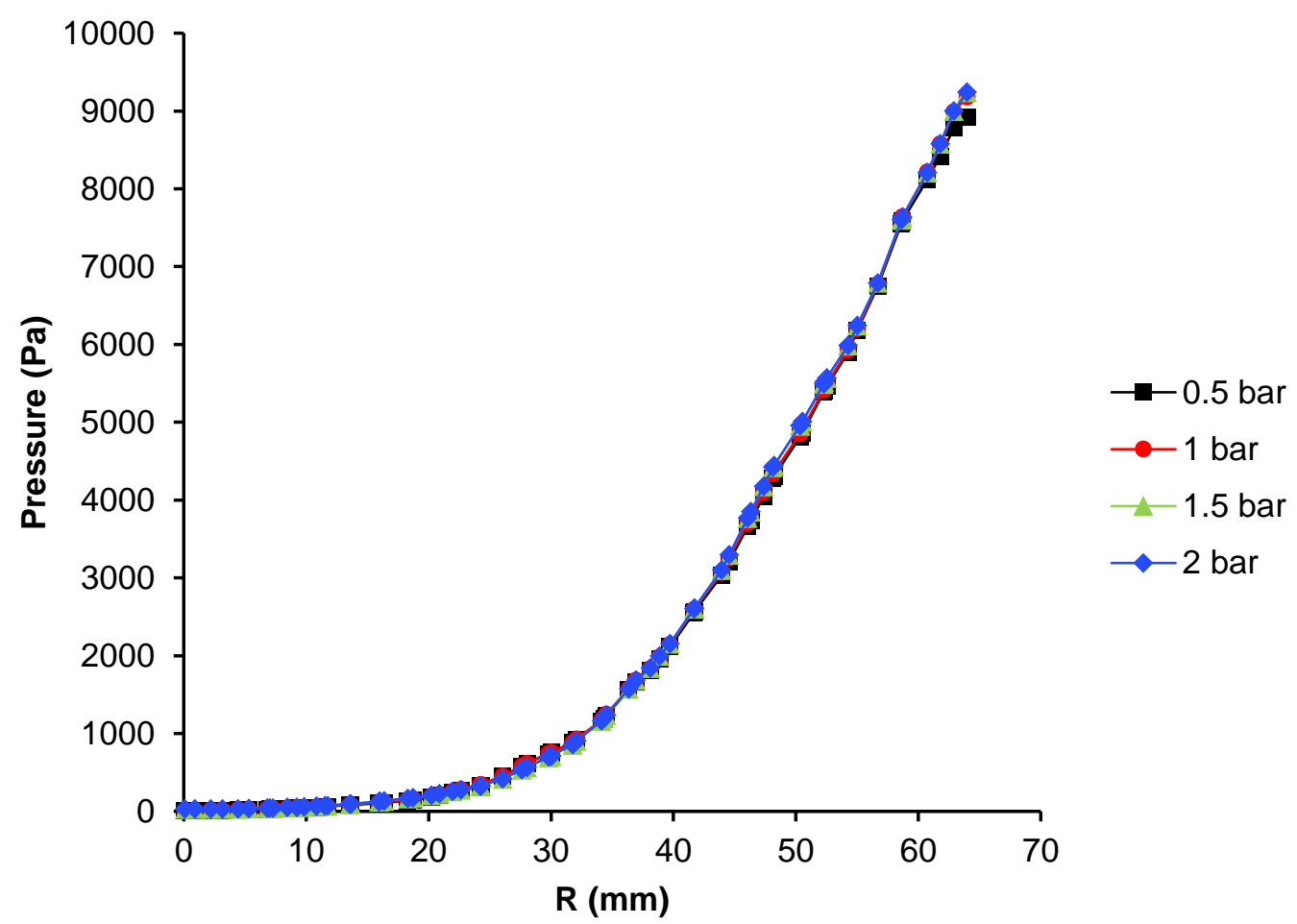

Fig. 16. Variation trend of blade dynamic pressure with radius at $800 \mathrm{rpm}$ 


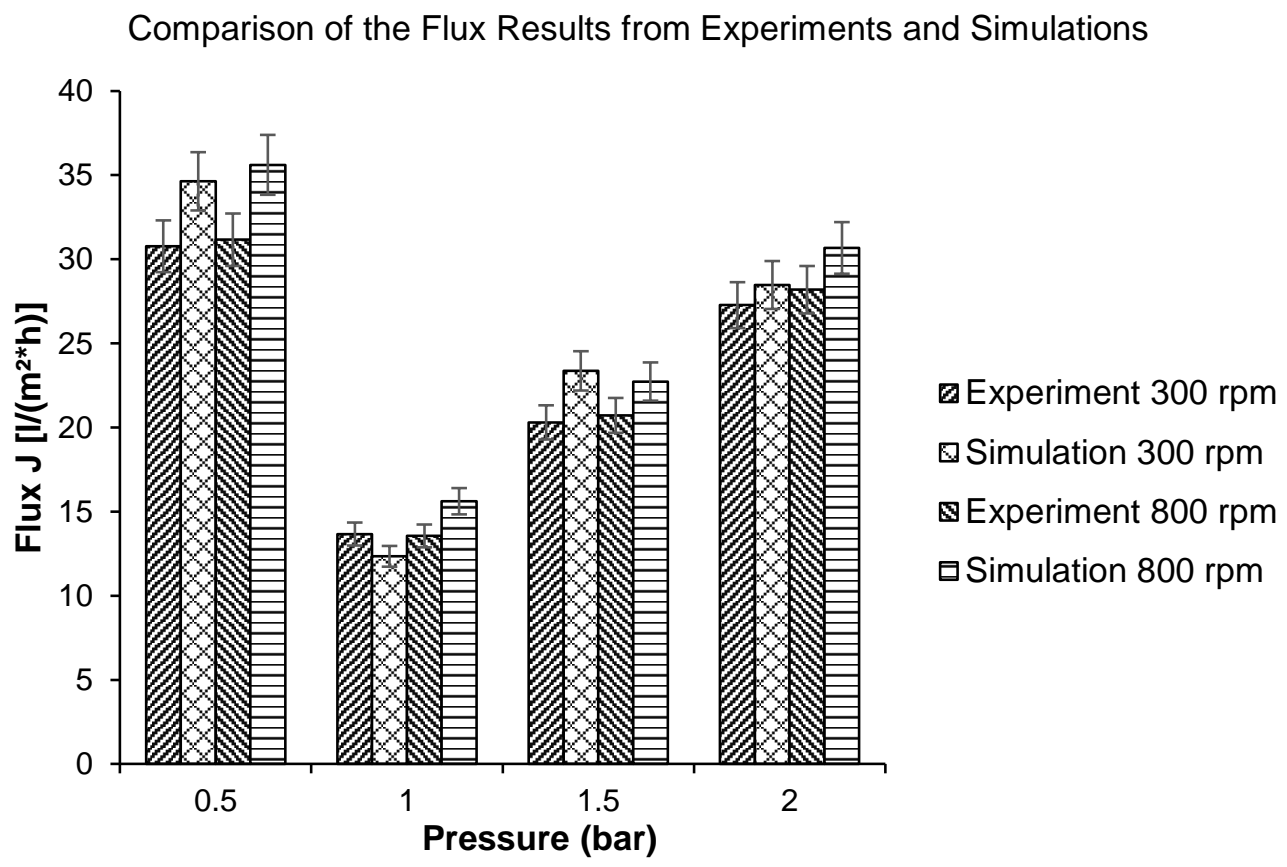

Fig. 17. Comparison of experimental and simulated flux results

\section{CONCLUSIONS}

With the blade dynamic cross-flow filtration equipment, and three membranes with different capturing size of molecule, the flux experiment of pulping black liquor was conducted, and the lignin content in the black liquor by the nanofiltration membrane NP010 was high. In this regard, the paper used CFD software Fluent to simulate the filtration of paper-making black liquor by the blade cross-flow nanofiltration membrane. The results of black fluid flux were obtained respectively by comparing the experiment and simulation, and the tangential velocity and blade stress on the blade cross-flow nanofiltration membrane surface were examined during the filtration process. The main conclusions are as follows:

1. The simulated flux results were similar to the experimental results. At $300 \mathrm{rpm}$ or 800 rpm, the flux of black liquor was optimal at a transmembrane pressure of 0.5 bar. According to the experimental and simulation results, it can be seen that the blade dynamic cross-flow uses $1 \mathrm{kDa}$ nanofiltration membrane to filter the black liquor at $300 \mathrm{rpm}$, and the average flux at $800 \mathrm{rpm}$ is about the same, but it consumes less energy and the pressure is less on the blade.

2. At $300 \mathrm{rpm}$ and $800 \mathrm{rpm}$, the maximum shear velocity on the membrane was $1.4 \mathrm{~m} / \mathrm{s}$ and $4 \mathrm{~m} / \mathrm{s}$, respectively, which was located at $R=64 \mathrm{~mm}$, that is, the blade edge. The tangential velocity on the membrane surface at $800 \mathrm{rpm}$ was three times that of 300 rpm, so the corresponding shearing stress on the membrane was also three times.

3. From the blade pressure variation in Figs. 13 and 14, it can be seen that at $800 \mathrm{rpm}$, the maximum pressure on the blade was 7 times that of $300 \mathrm{rpm}$. 


\section{ACKNOWLEDGMENTS}

The authors give sincere gratitude to Professor Wu Junfei and Professor Chen Fushan from Qingdao University of Science and Technology, Professor Hermann Nirschl and a fellow colleague Herr Zihim Lam from the Institute of Mechanische Verfahrenstechnik und Mechanik (MVM), which is affiliated to Institute of Karlsruhe Technology (KIT) for their academic assistance and help, also extend thanks to the Fund Project (2019GHY112040) for their support on finance.

\section{REFERENCES CITED}

Ahuja, D., Kaushik, A., and Singh, M. (2018). "Simultaneous extraction of lignin and cellulose nanofibrils from waste jute bags using one pot pre-treatment," Int. J. Biol. Macromol. 107(Part A), 1294-1301. DOI: 10.1016/j.ijbiomac.2017.09.107

Arkell, A., Olsson, J., and Wallberg, O. (2014). "Process performance in lignin separation from softwood black liquor by membrane filtration," Chem. Eng. Res. Des. 92(9), 1792-1800. DOI: 10.1016/j.cherd.2013.12.018

Al-Rudainy, B., Galbe, M., and Wallberg, O. (2017). "Influence of prefiltration on membrane performance during isolation of lignin-carbohydrate complexes from spent sulfite liquor," Sep. Purif. Technol. 187, 380-388. DOI: 10.1016/j.seppur.2017.06.031

Bott, R., Langeloh, T., and Ehrfeld, E. (2000). "Dynamic cross flow filtration," Chem. Eng. J. 80(1), 245-249. DOI: 10.1016/S1383-5866(00)00097-6

Bouzerar, R., Jaffrin, M. Y., Ding, L., and Paullier, P., O. (2000). "Influence of geometry and angular velocity on performance of a rotating disk filter," AIChE Journal 46(2), 257-265. DOI: 10.1002/aic.690460206

Costa, C. A. E., Pinto, P. C. R., and Rodrigues, A. E. (2018). "Lignin fractionation from E. globulus kraft liquor by ultrafiltration in a three stage membrane sequence," Sep. Purif. Technol. 192, 140-151. DOI: 10.1016/j.seppur.2017.09.066

De, S., and Bhattacharya, P. K. (1996). "Recovery of water and inorganic chemicals from kraft black liquor using membrane separation processes," TAPPI J. 79(1), 103-111.

Domínguez-Robles, J., Espinosa, E., Savy, D., Rosal, A., and Rodriguez, A. (2016). "Biorefinery process combining Specel $(\mathrm{R})$ process and selective lignin precipitation using mineral acids," BioResources 11(3), 7061-7077. DOI: 10.15376/biores.11.3.7061-7077

Domínguez-Robles, J., Tamminen, T., Liitiä, T., Peresin, M. S., Rodríguez, A., and Jääskeläinen, A. S. (2018). "Aqueous acetone fractionation of kraft, organosolv and soda lignins," Int. J. Biol. Macromol. 106, 979-987. DOI: 10.1016/j.ijbiomac.2017.08.102

Durruty, J. (2017). On the Local Filtration Properties of LignoBoost Lignin, Ph.D. Dissertation, Chalmers University of Technology, Gothenburg, Sweden.

Helander, M., Mattsson, T., Theliander, H., and Lindstrom, M. E. (2015). "Parameters affecting the cross-flow filtration of dissolved LignoBoost kraft lignin," J. Wood Chem. Technol. 36(1), 1-8. DOI: 10.1080/02773813.2015.1025284

Helander, M., Theliander, H., Lawoko, M., Henriksson, G., Zhang, L. M., and Lindstrom, M. E. (2013). "Fractionation of technical lignin: Molecular mass and pH effects," BioResources 8(2), 2270-2282. DOI: 10.15376/biores.8.2.2270-2282 
Hubbe, M., Alén, R., Paleologou, M., Kannangara, M., and Kihlman, J. (2019). "Lignin recovery from spent alkaline pulping liquors using acidification, membrane separation, and related processing steps: A review," BioResources 14(1), 2300-2351. DOI: 10.15376/biores.14.1.Hubbe

Humpert, D., Ebrahimi, M., and Czermak, P. (2016). "Membrane technology for the recovery of lignin: A review," Membranes 6(3), Article number 42. DOI: 10.3390/membranes6030042

Jaffrin, M. Y. (2008). "Dynamic shear-enhanced membrane filtration: A review of rotating disks, rotating membranes and vibrating systems," J. Membrane Sci. 324(12), 7-25. DOI: 10.1016/j.memsci.2008.06.050

Ji, Y., Guo, W., Zhao, L., Li, H., Lu, G., Wang, Z., Wang, G., Liu, C., and Xiang, W. (2011). "Development of an antigen-capture ELISA for the detection of equine influenza virus nucleoprotein," J. Virol. Methods 175(1), 120-124. DOI: 10.1016/j.jviromet.2011.04.016.

Jönsson, A. S., Nordin, A. K., and Wallberg, O. (2008). "Concentration and purification of lignin in hardwood kraft pulping liquor by ultrafiltration and nanofiltration," Chem. Eng. Res. Des. 86(11A), 1271-1280. DOI: 10.1016/j.cherd.2008.06.003

Kevlich, N. S., Shofner, M. L., and Nair, S. (2017). "Membranes for kraft black liquor concentration and chemical recovery: Current progress, challenges, and opportunities," Separ. Sci. Technol. 52(6), 1070-1094. DOI:

10.1080/01496395.2017.1279180

Liu, C., Si, C., Wang, G., Jia, H., and Ma, L. (2018). "A novel and efficient process for lignin fractionation in biomass-derived glycerol-ethanol solvent system," Ind. Crop. Prod. 111, 201-211. DOI: 10.1016/j.indcrop.2017.10.005

Manttari, M., Lahti, J., Hatakka, H., Louhi-Kultanen, M., and Kallioinen, M. (2015). "Separation phenomena in UF and NF in the recovery of organic acids from kraft black liquor,” J. Membrane Sci. 490, 84-91. DOI: 10.1016/j.memsci.2015.04.048

Toledano, A., García, A., Mondragon, I., and Labidi, J. (2010a). "Lignin separation and fractionation by ultrafiltration," Sep. Purif. Technol. 71(1), 38-43. DOI: 10.1016/j.seppur.2009.10.024

Toledano, A., Serrano, L., Garcia, A., Mondragon, I., and Labidi, J. (2010b). "Comparative study of lignin fractionation by ultrafiltration and selective precipitation,” Chem. Eng. J. 157(1), 93-99. DOI: 10.1016/j.cej.2009.10.056

Wallberg, O., and Jönsson, A. S. (2006). "Separation of lignin in kraft cooking liquor from a continuous digester by ultrafiltration at temperatures above 100 degrees C," Desalination 195(1-3), 187-200. DOI: 10.1016/j.desal.2005.11.011

Wallberg, O., Jönsson, A. S., and Wimmerstedt, R. (2003a). "Fractionation and concentration of kraft black liquor lignin with ultrafiltration," Desalination 154(2), 187-199. DOI: 10.1016/S0011-9164(03)80019-X

Wallberg, O., Jönsson, A., and Wimmerstedt, R. (2003b). "Ultrafiltration of kraft black liquor with a ceramic membrane," Desalination 156(1), 145-153. DOI:

10.1016/S0011-9164(03)00337-0

Article submitted: January 27, 2020; Peer review completed: April 25, 2020; Revised version received and accepted: Mary 21, 2020; Published: May 29, 2020.

DOI: 10.15376/biores. 15.3.5593-5615 